\title{
CASAS ESPAÑOLAS Y MATRIMONIOS AFROMAYAS EN MÉRIDA DE YUCATÁN, SIGLO XVI
}

\author{
Melchor Campos García \\ Universidad Autónoma de Yucatán
}

INTRODUCCIÓN

\begin{abstract}
Cuando Tomás López Medel, oidor de la Audiencia de Guatemala, proveyó ordenanzas para Yucatán durante su visita en 1552, mandó "que no pudiese entrar en los pueblos de indios, negro alguno, esclavo ni mestizo, sino yendo con sus amos y pasando de camino [y por un día]", y también autorizó a los caciques capturar a cualquier negro que anduviera por sus pueblos y entregarlos a las justicias españolas "para evitar con esto, robos, muertes y otros delitos que podían suceder". ${ }^{1}$ Como en toda la Nueva España, aunque no fue absoluta la prohibición de residencia por motivos morales y criminalización de los negros, ${ }^{2}$
\end{abstract}

Fecha de recepción: 20 de junio de 2016

Fecha de aceptación: 7 de febrero de 2017

\footnotetext{
${ }^{1}$ Ancona, Historia, p. 555.

2 En la Real Cédula del 23 de septiembre de 1580, el rey insistió en prohibir la convivencia arguyendo que los negros trataban "muy mal" a los indios, se servían de ellos y les quitaban lo que tenían, incluso "las mujeres e hijas, sin que puedan, ni se atrevan, a resistirlo, y demás de esto son corruptores de las costumbres y Evangelio y apostatan con los dichos indios". Lucena SALmoRAL, Regulación, pp. 79, 132.
} 
implicó permitir la convivencia de los negros con los diferentes grupos indígenas en los núcleos urbanos y centros laborales.

No obstante, pues, aquella prohibición y la exclusión para constituir "comunidades de derecho", ${ }^{3}$ la población esclava se encontraba inserta en las unidades domésticas de los conquistadores y pobladores. El tipo ideal de grupo doméstico español estaba constituido por una familia encabezada por un señor, o amo, asistida por un grupo de criados y sirvientes de diverso origen étnico; ${ }^{4}$ en Mérida podían encontrarse: mayas, nahuas o mexicas, mestizos (hijos de español e indígena), africanos y afrodescendientes (esclavos y libres).

En la Nueva España la presencia de diferentes modelos familiares tuvo un papel importante en el comportamiento

3 Andrés-Gallego, La esclavitud, pp. 255-257. La exclusión de formar pueblos con sus propias autoridades no fue absoluta, San Diego de la Gomera en Guatemala fue un pueblo fundado en 1611 a iniciativa del Conde de la Gomera, presidente de la Audiencia, como una estrategia para retirar a los africanos establecidos en poblaciones indígenas, y contó con su propio cabildo integrado por gente negra. Lokken, "Génesis", pp. 40-50. En Tabasco existió cierto reconocimiento político de la comunidad afrodescendiente mediante la costumbre de elegir "diputados" anuales para representar en materia económica lo que concernía "al bien común de cada uno de ellos". Cárdenas y Romero, Memoria (1811), pp. 120-121.

${ }^{4}$ García González, Familia, p. 14. El concepto de familia comprende un agregado de individuos con relaciones de parentesco (mediante matrimonio, sangre o rito). Toda vez que por unidad doméstica se entiende un grupo familiar (hogar) que establece relaciones entre sí o con personas no emparentadas que conviven, bajo el supuesto de "que articulan una economía común". Tuirán Gutiérrez, "Algunos hallazgos”, p. 279, p. 289, nota 12. El uso del concepto hogar-vivienda resulta más adecuado ya que carece de esa condición económica, LiRA, “Introducción”, p. 4. El término casa se usa en tres sentidos: a) vivienda o espacio agregado de residencia, b) "todas las personas" que la ocupan o pueblan, sean familiares o no, semejante al hogar-vivienda; por lo tanto, una casa puede contener varias familias, Cook y BoraH, Ensayos, vol. 1, p. 127, 128, 137, y c) linaje. Al menos que se indique otra cosa, en este ensayo se usará en las dos primeras acepciones, así como en el caso del ideal de casa poblada que comprendía a la familia, servidumbre y el afán de expandir el tamaño del grupo doméstico, Zamora, "Lo doméstico". 
observado en la selección de pareja y el matrimonio. ${ }^{5}$ Los indígenas mesoamericanos regulaban los enlaces prescindiendo de la voluntad de los contrayentes, dejando en manos de sus padres la responsabilidad de la selección, y era atribución de sus comunidades intervenir en los arreglos matrimoniales. ${ }^{6}$ Entre los mayas yucatecos del siglo xvI, los principales y caciques solían practicar la monogamia, admitir "una que otra concubina", e incluso sostener relaciones sexuales con las esclavas. La poligamia convivía en tensión con la persecución del amancebamiento. Por lo general, las mujeres mayas se casaban a los 14 años, pero el repudio o las separaciones entre cónyuges, incluyendo la disolución matrimonial, eran usuales, así como también contraer nuevas nupcias; en particular se destacaba la costumbre de huir o dejar al esposo o a la esposa. Este conjunto de prácticas mayas fue el foco del corregimiento de los franciscanos para ajustarlo al modelo cristiano.

Entre los originarios de África occidental y ecuatorial prevalecían las familias extensas, los lazos de parentesco y linajes matriarcales o patriarcales, con labores independientes de las mujeres en el mundo doméstico. ${ }^{8} \mathrm{El}$ matrimonio en la cultura bantú consistía en un "acto crucial”, exogámico al clan o descendientes de un mismo ancestro, y era "un negocio entre clanes" que desbordaba a los propios interesados, practicando la monogamia sin excluir la poligamia. ${ }^{9}$

Los diferentes modelos de familia fueron sometidos a reajustes basados en el paradigma católico. En la etapa previa

\footnotetext{
${ }^{5}$ Véase Gonzalbo Aizpuru, "La familia".

" Gonzalbo Aizpuru, "La familia”, pp. 9-10.

7 Lo aceptable era el matrimonio en estado de viudez. Para abundar sobre las costumbres matrimoniales entre los mayas, consúltese Peniche Moreno, Ámbitos, pp. 130-140.

${ }^{8}$ Kuznesof, "Raza”, pp. 378; Velázquez, Mujeres, pp. 76-78; Aguirre BeLtrán, La población, pp. 248-249.

9 Ngou-Mve, El África bantú, p. 23.
} 
a las resoluciones del Concilio de Trento (noviembre de 1563), el matrimonio era considerado un sacramento, se fundaba en la monogamia y la unión duradera, permitiendo la continuidad de las costumbres locales. ${ }^{10}$ No obstante, hubo una tendencia a prescindir del matrimonio entre parejas mixtas y españolas. ${ }^{11}$ La intervención de la corona consistió en regular la sociabilidad interétnica ${ }^{12}$ y prescribir los casamientos entre personas de la misma condición económica y calidad. En 1527 resolvió a favor de los enlaces de esclavos entre su propio grupo étnico para proteger los intereses de los propietarios. Por su parte, la Iglesia novohispana, en su aviso para indígenas de 1565, recomendó enlaces entre los grupos considerados puros (españoles, indígenas y castizos) y desalentó contraer nupcias con negros ante el riesgo de perder sus privilegios en los tribunales indígenas. ${ }^{13} \mathrm{~A}$ pesar de los intentos por imponer el matrimonio entre personas del mismo grupo étnico, en la práctica los africanos enfrentaron la desproporción numérica respecto a las mujeres del mismo origen. ${ }^{14}$

${ }^{10}$ Gonzalbo Aizpuru, "La familia”, p. 8.

${ }^{11}$ Bartolomé Zárate, regidor de la ciudad de México, informó a la corona que los esclavos negros apenas llegan a la Nueva España "se amanceban y están amancebados con indias naturales de ellas y con negras, así en casa de sus amos, como fuera de ellas y que los dueños de tales esclavos por los quitar de pecado los casan". Reseña de las causas y motivación de la Real Provisión dada en Valladolid, España, 10 de julio de 1538, en Lucena Salmoral, Regulación, pp. 55-56. ${ }^{12}$ Al gobernador de Yucatán le enviaron una cédula específica fechada en 1578, con la orden de evitar que los indios anduvieran en compañía de "mulatos, mestizos y negros porque, además que los tratan muy mal y se sirven de ellos, les enseñan sus malas costumbres y ociosidad", errores y vicios, así como ordenando a las justicias castigar a quienes encuentren en compañía de indios. "Al gobernador para que mulatos, mestizos y negros no anden en compañía de los indios", Madrid, 25 de noviembre de 1578, en Solís Robleda y BRACAMONTE y Sosa, Cedulario, p. 338.

${ }^{13}$ Cortés Jácome, “Los ardides”, pp. 44-46.

${ }^{14}$ La Real Provisión del 11 de mayo de 1527 mandaba procurar "en lo posible que, habiendo de casarse los negros, sea el matrimonio con negras. 
Desde esa perspectiva el afromestizaje se ha explicado en función de "la escasez de mujeres" afros. ${ }^{15}$

Las conclusiones del Concilio de Trento reafirmaron el modelo cristiano de matrimonio con la novedad de sostener la libre voluntad en la selección de pareja, sin interferencia ni coacción ajena a los contrayentes. Su aplicación fue organizada en el Tercer Concilio Mexicano, de 1585, y abrió un amplio espacio para uniones al margen de las normas, como en las ciudades de México y Guadalajara; sin embargo, se han observado efectos diferenciados ya que mientras los indígenas tendían a la indisciplina ante las normas familiares, los españoles y las castas se acercaban a ellas por la legitimidad de la descendencia. ${ }^{16} \mathrm{~A}$ pesar de las severas sanciones a la coacción durante el periodo colonial, en particular en el transcurso del siglo xvI, muchos matrimonios "fueron promovidos e incluso concertados por sus dueños". ${ }^{17}$ En el caso de la ciudad de México, en el siglo Xvi tardío y principios del XvII, de acuerdo con los cálculos de Colin Palmer, $80 \%$ de los matrimonios de esclavos se dio entre el mismo grupo racial. ${ }^{18}$

Pero las familias de los esclavos estuvieron marcadas por la dispersión entre los hogares-vivienda y las instituciones ya que

Y declaramos que éstos y los demás que fueren esclavos, no quedasen libres por haberse casado, aunque intervenga para esto la voluntad de sus amos". Lucena Salmoral, Regulación, p. 33.

${ }_{15}$ Para efectos prácticos utilizaré el término afro para referirme a la población africana y afrodescendiente residente en Mérida.

${ }^{16}$ Gonzalbo Aizpuru, "La familia”, p. 18. El matrimonio no tuvo la misma importancia en distintas regiones novohispanas; en el caso de Guadalajara, véase CAlvo, La Nueva Galicia, pp. 65-75; CASTAÑEDA, “La formación”, p. 81. 17 Velázquez, Mujeres, p. 252. Cuando los propietarios de esclavos no consiguieron la prohibición de los matrimonios de los esclavos, ya que la corona confirmó el derecho de los africanos a la "vida conyugal", "optaron los amos por forzarlos a uniones a su antojo" y obstaculizaron la "libre cohabitación", propiciando los amancebamientos con mujeres indígenas. AgUiRRE BELTRÁn, La población, pp. 252-255. Véase también Cortés Jácome, “Los ardides”.

18 Palmer, "México y la diáspora", p. 33. 
los amos estuvieron reacios "a facilitar la vida conyugal de sus esclavos" ${ }^{19}$ y toleraron las relaciones consideradas ilegítimas. ${ }^{20}$ Gonzalo Aguirre Beltrán concluyó que los esclavos no fundaron "verdaderas familias" sino hasta que la población afro y descendiente se incrementó, ${ }^{21}$ aunque los estudios actuales sugieren que sin lugar a dudas "la aglomeración y la promiscuidad en el interior de las viviendas propiciarían las relaciones irregulares, a ello se unió la convivencia con grupos de diferente origen étnico y cultural". ${ }^{22}$ Incluso se ha planteado que la excepción para los africanos y sus descendientes fue mantener relaciones estables, y la norma, el "vagabundeo sexual en todas sus formas", por lo que fracasaron los intentos de amoldar sus comportamientos al modelo familiar de Trento. ${ }^{23}$

De acuerdo con los comportamientos observados en ciudades novohispanas, ¿se puede encontrar que la corona y la Iglesia fracasaron también en moldear matrimonios endogámicos en la Mérida del siglo xvi?, ¿fueron la promiscuidad y las relaciones irregulares motivadas por la aglomeración pluriétnica en las casas españolas?, más aún, ¿constituyeron los matrimonios afroindígenas excepciones a la regla del "vagabundeo sexual en todas sus formas"? Un estudio reciente concluyó que por las restricciones para celebrar matrimonios mixtos, por la baja presencia afro y la cercanía de los grupos, de 1595 a 1600 se registraron escasas 72 nupcias afromayas. ${ }^{24}$ Otros estudios encontraron 52 enlaces de afros con indígenas/mestizas, 43 con mujeres

\footnotetext{
19 Gonzalbo Aizpuru, “El orden de la familia”, p. 35.

20 VelázQuez, Mujeres, p. 249.

21 Bernand, Negros, pp. 30-31. En su obra clásica sobre la población negra Aguirre Beltrán sostiene que la esclavitud "hizo imposible aun la simple unión del negro con la negra bajo el patrón occidental del matrimonio monógamo”, en particular durante los siglos Xvi y Xvir. Aguirre Beltrán, La población, pp. 249-250.

22 Gonzalbo Aizpuru, "La familia”, p. 11.

23 Camba Ludlow, Imaginarios, pp. 122-123.

24 Victoria Ojeda y Sánchez, “Interetnicidad”, pp. 26, 32.
} 
afrodescendientes, ${ }^{25}$ "and the existence of many informal unions that went unrecorded in the parish books" ${ }^{26}$ Las respuestas se ajustan al marco novohispano del fracaso.

Cierto que en el siglo xvi, la ciudad de Mérida no se encontraba entre las urbes novohispanas de mayor presencia africana, ${ }^{27}$ como tampoco lo fue a lo largo del periodo colonial. Las cifras son evasivas pero se ha ofrecido como regla que "había casi tantos africanos como españoles". ${ }^{28}$ Pues bien, de 1542 a 1550 Mérida tenía 70 vecinos, que se incrementaron a 200 en 1562; luego, en la década siguiente, hubo un regreso a las cifras iniciales. En 1588 su población llegó a 300 vecinos, con un paulatino crecimiento alcanzó la cifra de 400 españoles en $1639 .{ }^{29}$ La estimación más importante acerca de la presencia negra en Mérida identificó 84 esclavos (44 hombres y 8 mujeres) y 32 libres (26 varones y 6 mujeres) durante el periodo de 1567 a $1601 .{ }^{30}$ Las cifras sobre las que se basan las conclusiones antes referidas representan

${ }^{25}$ Fernández Repetto y Negroe Sierra, Una población, cuadros 3 y 4, pp. 28 y 32; ResTAll, The Black Middle, tabla 7.2, p. 260.

${ }^{26}$ Restall, The Black Middle, p. 259.

27 Se ha estimado, con sus reservas, que 50000 personas habitaron en la ciudad de México durante el siglo xvi, y los africanos y afrodescendientes representaron entre 35 y $40 \%$ a lo largo de los tres siglos coloniales. VeLÁzQUEZ, Mujeres, p. 19. Tlaxcala tenía 3000 personas de origen africano. BERNand, Negros, p. 32. Hacia 1574 en Puebla habitaron 500 negros y "muchos mulatos" o afroindígenas. Paredes Martínez y Lara Tenorio, "Los trabajadores", p. 25. Y en Antequera vivieron 150 esclavos y 350 españoles en 1569. MotTa SÁnchez, “La población negra”, p. 209.

${ }^{28}$ Restall, The Black Middle, p. 17. Se carece de datos confiables para la ciudad de Mérida del siglo xvi, de manera que aquí se usa con cierta precaución la relación propuesta por Restall, ya que para 1605 el cálculo conocido para la jurisdicción de Mérida, o de su catedral, arrojó la cifra de 1000 negros y mulatos y 2000 la de españoles. Cook y Borah, Ensayos, vol. 2, pp. 87-88; por lo tanto, la relación sería de 0.5 personas de origen africano por cada español en el distrito que se extendía más allá de los límites de la naciente ciudad.

${ }^{29}$ Campos García, "Esclavitud”, p. 25.

30 Fernández Repetto y Negroe Sierra, Una población, cuadros 1 y 2, pp. 27-28. 
grosso modo, un tercio de la población encontrada en los registros matrimoniales de los "naboríos" de Mérida entre 1563 a 1610. En la fuente encontramos a 122 propietarios de esclavos (109 españoles y 13 españolas), y 324 africanos y afrodescendientes (69 libres y 255 esclavos o sirvientes domésticos). ${ }^{31}$

Los matrimonios observados corresponden al intervalo de 1567 a 1610, un periodo de tránsito hacia la aplicación del modelo de Trento. Este conjunto se acerca a la relación negrosespañoles y ofrece analizar con mayor certeza las actitudes hacia el matrimonio afroindígena, la coacción como factor propiciatorio de aquellos enlaces, la composición familiar en las viviendas españolas y la formación de una naciente comunidad afromaya en la Mérida del siglo xvi. ${ }^{32}$

\section{CASA POBLADA Y RELACIONES AFROMAYAS}

En la etapa formativa de Mérida (1542-1610), como en otros centros novohispanos, las viviendas de los españoles de distintas clases y jerarquías, de los "más principales" o beneméritos, principales, oficiales de la administración colonial, jerarquías eclesiásticas, mercaderes y vecinos en general, fueron microcosmos de la diversidad étnica ordenados por el patriarcalismo, condiciones y calidades de las personas. En el recinto dedicado a la ciudad de los conquistadores, con sus construcciones eclesiásticas y civiles, se encontraba la casa poblada de los españoles (esposa, hijos y, en no pocas ocasiones, parentela), ${ }^{33}$ los indígenas

31 Véase Campos García, “Esclavitud”, pp. 26-27. Nuestros datos representan un cambio significativo en la percepción de una presencia poco importante de los afros en Mérida, incluso respecto a las 136 personas encontradas por Victoria OJeda y Sánchez, “Interetnicidad”, pp. 23, 32.

32 En este caso el término comunidad no se usa a la manera de pueblo indígena, designa al grupo de afros y afromayas que ocuparon un espacio social en la Mérida del siglo Xvi, tejieron complejas relaciones familiares y de solidaridad con su propia parroquia y fondos comunes como las cofradías.

33 A fines del siglo xvi se había consolidado la reunión de matrimonios de los 
mayas procedentes de los pueblos encomendados para el servicio personal, así como los naboríos que habitaban en algunos pueblos en los alrededores de la ciudad, los nahuas (xochimilcas, texcocanos, azcapotzalcas y tlaxcaltecas), los criados españoles, ${ }^{34}$ los esclavos y negros procedentes de distintos grupos culturales de África y sus afrodescendientes (mulatos, morenos, pardos, etc.). ${ }^{35} \mathrm{El} \mathrm{microcosmos} \mathrm{del} \mathrm{espacio} \mathrm{doméstico} \mathrm{donde} \mathrm{coincidían}$ hombres y mujeres de la servidumbre multiétnica fue propicio para cultivar relaciones que enlazaran a los afros con los indígenas en matrimonio, o bajo el perseguido amancebamiento.

En el periodo fundacional de Mérida la población negra no tuvo un lugar destinado como residencia, como aseveró Matthew Restall que lo fue el pueblo de Santa Lucía, ${ }^{36}$ ya que existen

conquistadores y primeros pobladores que traían de España o de otras colonias a sus esposas, en no pocas ocasiones acompañados de criados españoles. MoLINA Solís, Historia, pp. 270-272. Un acucioso estudio sobre los pobladores de la Mérida del siglo xvi y sus familias en Rubio Mañé, Discurso.

34 Alonso Sánchez fue a España en 1572; cuando se aprestó a regresar a Yucatán, solicitó licencia para traer consigo un “criado para su servicio”. AGI, $I$, leg. 2055, no. 4. Francisco Palomino, protector y defensor de indios de Yucatán, en su súplica de licencia para regresar a la provincia en 1579, dejó asentado su estatus y cantidad de servicio común: "licencia para que pueda llevar para su servicio dos criados que es lo que ordinariamente trae de ordinario consigo”. AGI, I, leg. 2059, n. 157, f. 1.

35 De manera operativa uso los términos negro, mulato, moreno e indio como etiquetas de raza, asignadas sobre la base de características fenotípicas y culturales (como la religión) socialmente escogidas para distinguir a un grupo humano de otro en la Mérida del siglo xvi; en cambio, el concepto de etnia enfatiza los aspectos culturales compartidos y se usa calidad en el sentido que tuvo en el contexto colonial de distinción como resultado del cruzamiento de distintas variables: raza, condición, cultura y posición socioeconómica. MAsFerrer León, Muleke, pp. 54-56; Velázquez Gutiérrez, Mujeres, pp. 52-54; DunCAN, “¿Existen las razas?”, pp. 218-219.

36 Restall, The Black Middle, p. 216. El autor citado le da continuidad a un equívoco de Rubio Mañé, quien aseveró que el barrio de Santa Lucía - al norte de la traza de la ciudad - fue levantado "para los negros esclavos”; véase RubIo Mañé, Discurso, p. 11. Por nuestra parte no descartamos el asentamiento de negros y afrodescendientes en aquella localidad, como se verá más adelante, 
indicios de que los esclavos moraban en los espacios posteriores de la vivienda principal ocupada por los españoles, donde se encontraban los servicios y las habitaciones de la servidumbre. ${ }^{37}$ Las “casas reales” donde habitaba el gobernador capitán general ilustran la configuración de una residencia de mayor estatus:

El edificio era de planta baja de un solo piso sin galerías exteriores ni interiores [...]. En el interior, el primer patio era un paralelogramo rectángulo sembrado de naranjos y otros árboles, sin corredor alguno, y cerrado en sus cuatro lados por las paredes de las piezas correspondientes a los salones, oficinas, cámaras y demás dependencias de la casa, provistas de bajas y estrechas puertas y elevadas ventanas. Un segundo patio estaba destinado para desahogo de los criados, mientras que el tercero, mucho más espacioso, servía de huerta y jardín, y extendía sus endebles muros de tierra y piedra a lo largo de las calles lateral y trasera. ${ }^{38}$

Esta configuración básica prevaleció en las casas con mediana opulencia: "A typical middle-bracket residence would consist of a large entry or zaguán, with the receiving room to one side and other rooms flanking it on both sides. The kitchen was normally in the back, and it helped from the first patio along with the other rooms. Beyond it was the second patio, servants quarters, and the corrals". 39

Nancy Farriss observa que "las casas más grandes [de Mérida], que eran la versión local del ideal señorial, estaban atendidas por un enjambre de semaneros de los poblados que ayudaban a niñeras, jardineros, lacayos, mozos de cuadra, lavanderas y

pero se trató de un pueblo de indios con sus propias autoridades. Campos García, "Esclavitud”, p. 41.

37 Campos García, "Esclavitud”, p. 41; Victoria Ojeda y Sánchez, "Interetnicidad”, pp. 14-15, 32.

${ }^{38}$ Molina Solís, Historia, pp. 278-279.

${ }^{39}$ Espejo-Ponce Hunt, “Colonial Yucatan”, p. 205. 
otros sirvientes que constituían el personal permanente". ${ }^{40} \mathrm{Al}$ servicio doméstico eran destinados indios e indias de manera temporal y rotativa. Los primeros se ocupaban de llevar agua, alimentar con zacate a los caballos, proporcionar leña y asear la residencia; en cambio a las mujeres se les ocupaba en moler maíz y elaborar tortillas, cuidar niños y amamantar a los de brazos. ${ }^{41}$ En casas de algunos importantes encomenderos, como lo reveló el gobernador en 1575, había mujeres negras que tenían a su cargo las labores "de guisar, de comer y lavar". ${ }^{42}$ Criados y criadas asumían cargos de alguna responsabilidad y confianza como: mozos de cuadra, jardineros, cocineras y niñeras; y en los hogares vivienda de mayor importancia trabajaban "a las órdenes de un negro o un mulato (la mitad de las veces un esclavo) que servía como mayordomo". ${ }^{43}$

La práctica coactiva de arraigar mujeres indígenas en las viviendas españolas radicaba en la necesidad de mano de obra para desempeñar labores que las esclavas no estaban obligadas a realizar y que, por alegatos de los propios españoles, las africanas desconocían: básicamente la preparación del maíz. Trabajo que, por testimonio de las autoridades y encomenderos, en ausencia de la tortilla, la ingesta de la mazorca hervida (elote sancochado) afectaba la salud de los españoles. Las mujeres afros no sabían desempeñar ese trabajo, o por el costo de las esclavas era preferible mantenerlas fuera de esas faenas y, por supuesto, las mujeres blancas ni remotamente estaban dispuestas a ocuparse de ello. La necesidad de alimentarse con tortilla de maíz en las casas de españoles era de vital importancia, y la cantidad a

\footnotetext{
${ }^{40}$ FARriss, La sociedad maya, p. 95.

${ }^{41}$ Solís RobledA, Bajo el signo, pp. 54-55; FArRiss, La sociedad maya, pp. 94, 98.

42 "Informe del gobernador de Yucatán sobre el servicio personal de los indios, Mérida, a 16 de septiembre de 1575”, en Solís RobledA, Contra viento, p. 297.

${ }^{43}$ FARriss, La sociedad maya, p. 171.
} 
procesar estaría en relación con el tamaño de la familia española, los criados, los sirvientes y los esclavos. ${ }^{44}$

La división étnica del trabajo en las viviendas españolas forjada en la fase formativa de Mérida perduró por largo tiempo, como se confirma en el alegato a favor de mantener el sistema de tandas de indias, elaborado en 1722 por Antonio Ruiz de la Vega, procurador de los tres principales cabildos de la Península:

[...] y las mujeres [de los blancos] para el gobierno de sus casas y cuidado de sus maridos, las que tampoco - por su naturaleza débil no usada al trabajo de beneficiar y moler maíz - pudieran tolerarlo, y más habiendo de ser perpetuo sin ningún intervalo, porque cada día es menester beneficiar y moler el pan que se ha de comer. Y siempre fuera lo mismo sin tener a quien volver los ojos para que las ayudasen, porque si hay algunas criadas que se mantienen en las casas, éstas sirven en ayudar a dichas indias [de los pueblos procedentes de los pueblos] y en otros ejercicios precisos para el alivio de la vida humana, no habiendo - como no hay - caudales para comprar negras [esclavas] $[\ldots]^{45}$

La corona insistió en pedir a sus gobernadores que en la provincia se otorgara buen trato a los indígenas y procurar su conservación, pidiendo remediar los abusos cometidos contra ellos. En particular, prohibía desarraigar mujeres y niñas de las encomiendas sin autorización de las autoridades indígenas y coloniales y, en su caso, también obtener el consentimiento

${ }^{44}$ Sobre una media entre el consumo óptimo por adulto de $1.17 \mathrm{~kg}$ de maíz al día y un mínimo de $0.667 \mathrm{~g}$, el consumo medio sería de $920 \mathrm{~g}$ al día. AskinasY, El problema, pp. 34-35. En una casa poblada con dos adultos y tres niños (un consumo de adulto) y su servidumbre promedio se tendrían 10 adultos. Por lo tanto, se requerían procesar $9.2 \mathrm{~kg}$ de maíz al día y a la semana cerca de 64 kilos. 45 "Representación del procurador de Mérida, Campeche y Valladolid al gobernador pidiendo se suspenda la ejecución de la provisión que cancela el servicio personal, Mérida, a 3 de septiembre de 1722”, en Solís Robleda, Contra viento, p. 39. 
de ellas. El desarraigo de mujeres y niñas mayas sin ese triple consentimiento acarrearía problemas legales; por ejemplo, Diego Osorio, encomendero de Tecay, en el asiento de Tizimín, fue denunciado por sacar, con autorización del cacique, "dos muchachas huérfanas de padre y madre, para criarlas", bajo la promesa de que cuando tuvieran edad las enviarían de regreso al pueblo para su casamiento. ${ }^{46}$ Este desarraigo de huérfanas fue acuñado como uso y costumbre entre los encomenderos de Yucatán, ${ }^{47}$ práctica que, ya entrado el siglo xviI, en 1636, el gobernador Andrés Pérez Franco denunció como el arrebato de huérfanas mayas de manos de sus parientes "con el pretexto de criarlas y enseñarles la doctrina". 48

Pero resulta que la corona no solo prohibió que los negros habitaran en pueblos de indígenas, sino que también envió reiteradas órdenes para no casar negros con mujeres indígenas. Sin embargo, los informes continuos de abusos y prácticas contrarias a las disposiciones reales continuaron. En 1573, el rey tenía informes de que los encomenderos se servían de indias huérfanas, "con sus negros y mulatos", cargándolas de trabajo forzoso, y lo más escandaloso resultaba que a ellas, sin edad "ni discreción” para entender lo que era el matrimonio, las compelían a contraer nupcias con los esclavos para mantenerlas en estado de servidumbre. Incluso, que los negros y mulatos tenían indios a su servicio. ${ }^{49}$ En realidad, la corona no quería casamientos entre

\footnotetext{
${ }^{46}$ Las huérfanas extraídas por Osorio fallecieron por el año de 1580, Testimonio de Juan Huchim, Tizimín, 21 de noviembre de 1583, en OrTiz YAm y Quezada (eds.), Visita de Diego García, p. 141.

${ }^{47}$ Confesión de Alonso Díaz, Valladolid, 17 de diciembre de 1583, en OrTIZ Yam y Quezada (eds.), Visita de Diego García, p. 156. En la naciente ciudad de Mérida radicaron grupos desarraigados de sus territorios y culturas como los africanos, mexicas y tlaxcaltecas, así como gente maya extraída de sus pueblos originarios, pero sin perder del todo el vínculo con su contexto cultural.

${ }^{48}$ Citado en Solís Robleda, Bajo el signo, p. 70.

49 AGI, M, 2999, L. 3, f. 659/2, Cédula a Francisco Gixón, Madrid, 21 de abril de 1573, en "Yucatán desde diciembre de 1572 hasta julio de 1602". "Libro
} 
personas con estatus asimétricos, de esclavos con indígenas reducidas a vasallaje, forzadas a la servidumbre pero libres, y de limitada comprensión de las implicaciones de la esclavitud.

En 1575, el gobernador relató al rey los problemas para detener los matrimonios desiguales, que reproducimos en extenso por su importancia:

Vuestra Magestad me envió a mandar por su real cédula sobre que pusiese remedio en los casamientos que hacen entre negros esclavos e indias, habiéndolo bien entendido hallé haberse hecho a Vuestra Majestad verdadera relación y ser grande el exceso que en esto hay y cosa digna de remedio porque de un esclavo hacen dos siguiendo la mujer la voluntad del marido y éste la de su señor, atraénlas a esto con vanas promesas y sutiles inducimientos que suelen ser poco menester por ser gente simple y fácil y de ligero se creen, es lástima lo que en esto pasa y la mala suerte de gente que destos se engendra que abraza en sí lo peor de sus dos principios [....$^{50}$

Pero el gobernador en su informe al rey apuntaba hacia el temor que atizaba el prejuicio contra las uniones entre africanos y mujeres mayas: que de esa unión los descendientes heredaban lo peor de ambas "razas”. Armado con la Cédula Real y sus prejuicios raciales, el gobernador visitó al obispo para detener los matrimonios entre calidades desiguales, pero la respuesta no fue la esperada, en cambio recibió la amenaza de excomunión si insistía en prohibir esas bodas. ${ }^{51}$ En 1577 le tocó al defensor de indios, Francisco Palomino, informar a la corona que la motivación de los encomenderos para enlazar a las indias con

donde se asientan los despachos de la provincia de Yucatán. Tocantes a oficios." López Cogolludo, Historia, p. 211. Véase también Solís Robleda y Bracamonte y Sosa, Cedulario, p. 266.

${ }^{50}$ AGI, $M$, leg. 359, n. 15, Oficio del gobernador Francisco Velázquez de Gixón, Mérida, 26 de marzo de 1575.

${ }^{51}$ AGI, $M$, leg. 359, n. 15, Oficio del gobernador Francisco Velázquez de Gixón, Mérida, 26 de marzo de 1575. 
sus "negros esclavos” era perpetuarlas en el servicio. Las indígenas contraían matrimonio con los negros, “otras con mulatos vagueando calles, de tienda en tienda con quien quieren o las quieren" sin retornar a sus pueblos, tratándolas como esclavas, cosa que no ocurría en sus pueblos, al casarse con sus “iguales”, pero lo preocupante era la descendencia de "esta mala casta de mulatos y negros que nacen de las indias”, gente libre peligrosa “por ser los españoles tan pocos". ${ }^{52}$

El presunto desacato no paró ahí y la promesa de regresarlas a sus pueblos para que se casaran con los suyos tampoco fue del todo satisfecha, ya sea por la muerte prematura de algunas de las "muchachas" huérfanas, por unirse con afros libres o bien por casarse en la ciudad. En la flota de 1581, el gobernador de Yucatán, Guillén de las Casas, recibió de nuevo la orden de evitar que los negros "vivan donde puedan tratar y comunicar con los indios”, pero lo que más le importaba eran "los casamientos de negros con indias" por considerarlos dañosos "para muchas cosas”, y el asunto de gravedad consistía en que, a pesar de las recomendaciones del rey, "los prelados y sus curas jamás” cumplían, incluso con sus notificaciones locales de no celebrar esa clase de nupcias. El gobernador relataba que en el transcurso de la última semana de marzo de 1582, a pesar de su intervención, se había celebrado el sacramento ya que los curas obedecían al obispo. ${ }^{53}$ ¿A quiénes se refería el gobernador con el término negro? Parece que rechazaba los enlaces de los esclavos con indígenas, sin que en esa ambigüedad no excluyera a los libres.

En cambio, las denuncias franciscanas ${ }^{54}$ del defensor de indios y de las autoridades provinciales enfatizaron en erradicar

${ }^{52}$ Camba Ludlow, Imaginarios, p. 61; Cédula, Aranjuez, 13 de mayo de 1579, AGI, M, 2999, Leg. 2, ff. 361v-362; Ortiz Yam y Quesada (eds.), Visita de Diego García, p. 34.

${ }^{53}$ AHN, DC, 25, núm. 54, f. 6, Guillén de las Casas, Mérida, 25 de marzo de 1582.

${ }^{54}$ Correspondencia dirigida al Rey en 1572, citada por Restall, The Black Middle, p. 258. 
las nupcias de negros o esclavos con indígenas arraigadas sin consentimiento, mediante seducciones o promesas ilusas, por la necesidad de fijar a la servidumbre indígena. Pero lo cierto es que desde el Concilio de Trento en 1563, la Iglesia estableció el modelo de matrimonio libre de coacción, y aunque fue adoptado en el Tercer Concilio Mexicano de $1585,{ }^{55}$ parece que ya se aplicaba desde 1575, como lo sugiere la amenaza de excomunión recibida por el gobernador cuando trató de evitar los matrimonios de negros con indias.

De las recomendaciones de matrimonios endogámicos respecto a los grupos raciales bajo la fórmula de "procúrese en lo posible", se admitió la libertad en las uniones de negros con indígenas, ${ }^{56}$ pero la mayor vigilancia se centró en los amancebamientos o relaciones ilícitas de los afros con las mujeres mayas procedentes de los pueblos del interior de la Península. En 1575, la ciudad de Mérida denunció como falso el informe llevado a la Audiencia de México acerca de "la gran cantidad" de indígenas mozas, solteras y viudas que se extraían de los pueblos hacia la ciudad de Mérida, donde eran retenidas contra su voluntad y “asoldadas", sin sueldo, en casas de los españoles donde los "criados y esclavos" les daban malos ejemplos. ${ }^{57}$ El gobernador Velázquez de Gixón también impugnó la acusación presentada en contra suya por tener muchas indias en su vivienda y, en particular, según sus propias palabras: "que tenía descuido en el vivir mal con ellas mis criados y esclavos". ${ }^{58}$ De manera que el modelo tridentino puso la mira en las relaciones sexuales fuera de matrimonio y en uniones como el concubinato, contrarias al buen vivir en las viviendas de españoles.

\footnotetext{
55 Villafuerte, “Casar y compadrar”, p. 62.

56 Villafuerte, “Casar y compadrar”, p. 64.

57 AGI, $M, 214$, núm. 18, Alonso de Herrera, procurador de la ciudad de Mérida, a la Real Audiencia de México, 28 de febrero de 1578.

58 AGI, $M, 214$, núm. 18, Respuesta de Francisco Velázquez de Gixón a la Audiencia de México, Mérida, 18 de marzo de 1575.
} 
Pero las indígenas al parecer no fueron del todo pasivas o coaccionadas para establecer relaciones con los afros, existen por lo menos algunos indicios de la disposición de las mujeres mayas de cruzar la barrera de color. Un año antes de las ordenanzas de López Medel, en 1551, un informe describe que cuando los negros entraban a los pueblos indígenas surgían "muchos inconvenientes", en especial, causaban "que roben a los indios y les tomen sus mujeres e hijas". ${ }^{99}$ Como se discutió arriba, entre la etnia maya existía la práctica de la huida de mujeres con otros hombres abandonando al marido, de modo que sin negar la existencia de casos de rapto o violencia, las quejas de los religiosos pudieran expresar la indignación de los varones mayas por la fuga femenina con los africanos (extranjeros); incluso pudiera también manifestar los propios prejuicios de los franciscanos. Dos décadas más tarde, en 1574 el virrey de la Nueva España aportó otro testimonio cuando describió la inclinación de las indígenas por los negros. ${ }^{60}$ Aunque el virrey no se refería específicamente a las mayas, en 1605 el gobernador de Yucatán, Carlos de Luna y Arellano, de manera parecida, observaba de forma lastimosa: "el pecado sensual que se acostumbra porque [a]demás de la natural inclinación de las indias, la co[n]stelación de la tierra las inclina demasiado y entre los españoles se crían en su servicio muchas indizuelas $[\ldots] "{ }^{61}$

\footnotetext{
${ }^{59}$ Carta de Francisco de la Torre y otros religiosos al Rey, Yucatán, 20 de mayo de 1572, citado por Victoria OJEda y Sánchez, "Interetnicidad", p. 13, 26 (nota 86). La prohibición de la circulación de negros en pueblos indígenas de Yucatán proveída en 1551 fue motivada precisamente por la información de la toma de mujeres indígenas. "A la Audiencia de los Confines sobre encomiendas y contra la presencia de negros en los pueblos de indios de Yucatán", Valladolid, España, 9 de septiembre de 1551, en Solís Robleda y Bracamonte y Sosa, Cedulario, p. 114.

${ }^{60} \mathrm{El}$ virrey observó que muchas indígenas preferían uniones con negros y esclavos, en lugar de con sus maridos. Mörner, La mezcla de razas, p. 40.

${ }^{61}$ AGI, $M, 359$, r. 9, núm. 48, Carta de don Carlos de Luna y Arellano, Mérida, 6 de abril de 1605.
} 
El gobierno y el cabildo de Mérida tenían el acuerdo de mantener los repartimientos de mujeres indígenas por tandas a las viviendas de los españoles, mientras que el clero y los encomenderos actuaban en alianza contraria a la preferencia trazada desde Madrid de prohibir los matrimonios de esclavos con indígenas. De acuerdo con Palomino, en la ciudad había "gran cantidad de indias viudas, solteras y casadas, y muchachos contra su voluntad servirse dellos y había personas que tenían en sus casas de a diez y doce años de servicio" sin pago $^{62} \mathrm{y}$, como ya dijimos, se trataba de perpetuarlas en el servicio casándolas con esclavos.

\section{LOS MATRIMONIOS AFROMAYAS}

EN LOS REGISTROS ECLESIÁSTICOS

¿Cuándo empiezan los asientos nupciales de africanos y afrodescendientes? ¿Existen evidencias de endogamia doméstica como indicador de las denuncias del protector de indios Palomino? Y más aún, ¿`cuál fue la magnitud de los matrimonios afromayas?, y ¿qué repercusiones tuvo la visita de Diego García de Palacio en 1583? La información más confiable de la presencia negra en Mérida entre 1563 y 1610 se desprende del primer volumen de Matrimonios del Sagrario de la ciudad en la sección de casamientos de los naboríos. En esta fuente se tiene la cantidad de 1000 matrimonios para el periodo, y de ese conjunto, $12.6 \%$, en números absolutos 126, de los enlaces celebrados tenían por lo menos un(a) contrayente afro. Una primera observación radica en la ausencia de nupcias afros anteriores a 1567, lo que puede ser indicio de que se dio poca importancia al matrimonio cristiano hasta que empezó a aplicarse el modelo de Trento, como lo sugiere la amenaza de excomunión lanzada por el obispo al gobernador en 1575, lo que posibilitó denunciar uniones consideradas ilícitas entre africanos y afrodescendientes con mujeres

$\overline{62}$ AGI, $M, 359$, r. 9 núm. 48, Cédula, Aranjuez, 13 de mayo de 1579. 
mayas y pugnar por los matrimonios entre personas del mismo grupo étnico.

Tabla 1

MATRIMONIOS DE NABORÍOS EN MÉRIDA, 1563-1610

\begin{tabular}{lccc}
\hline Años & $\begin{array}{c}\text { Total } \\
\text { de enlaces }\end{array}$ & $\begin{array}{c}\text { Africanos } y \\
\text { afromayas }\end{array}$ & $\begin{array}{c}\text { Porcentaje por } \\
\text { quinquenios }\end{array}$ \\
\hline $1563-1564$ & 26 & & \\
$1565-1569$ & 70 & 10 & 14.0 \\
$1570-1574$ & 52 & 13 & 25.0 \\
$1575-1579$ & 196 & 18 & 9.0 \\
$1580-1584$ & 226 & 11 & 4.8 \\
$1585-1589$ & 145 & 14 & 9.6 \\
$1590-1594$ & 148 & 21 & 14.0 \\
$1595-1599$ & 97 & 10 & 10.3 \\
$1600-1604$ & 11 & 2 & 9.0 \\
$1605-1609$ & 29 & 27 & 93.0 \\
Total & 1000 & 126 & \\
\hline
\end{tabular}

Elaboración propia a partir de ASAY, $M$, vol. 1, 1567-1610.

Nota: Aunque las cifras del primer intervalo corresponden a dos, se incluyeron para evaluar el conjunto de registros matrimoniales de los naboríos de la ciudad integrada por mesoamericanos, africanos y afromestizos (esclavos y sirvientes libres). Véase Campos García, "Esclavitud", pp. 21-44; en el segundo quinquenio las nupcias entre negros y afroindígenas iniciaron en 1567.

De los 126 matrimonios africanos y afromayas del periodo encontramos 121 hombres afros y 5 indígenas, lo que demuestra que la barrera del color difícilmente fue cruzada por los hombres mayas. Pero del conjunto de mujeres contrayentes encontramos 57 afros, 60 indígenas y 9 sin identificador étnico. Podemos concluir que en general hubo equilibrio en el origen de las mujeres, cerca de $54 \%$ de las contrayentes fueron indígenas y $45 \%$ negras. A diferencia de los escasos matrimonios indioafros, los hombres 
afros y las indígenas estuvieron más dispuestos a establecer enlaces mixtos. Un desglose por quinquenios permitirá observar los matrimonios afroindígenas en el contexto posterior a las decisiones de Trento y del Concilio Mexicano de 1585, así como de las presiones a favor de uniones entre personas de igual calidad.

\section{Tabla 2}

CONTRAYENTES EN MATRIMONIOS AFROS DE MÉRIDA, 1563-1610

\begin{tabular}{lcccc}
\hline & Hombres & \multicolumn{3}{c}{ Mujeres } \\
\cline { 2 - 5 } Intervalos & Afros & Afros & Indígenas & $\begin{array}{c}\text { Sin etiqueta } \\
\text { racial }\end{array}$ \\
\hline $1565-1569$ & 10 & 5 & 5 & \\
$1570-1574$ & 13 & 6 & 5 & 2 \\
$1575-1579$ & 15 & 4 & 10 & 1 \\
$1580-1584$ & 11 & 2 & 9 & \\
$1585-1589$ & 14 & 12 & 2 & \\
$1590-1594$ & 20 & 11 & 9 & 3 \\
$1595-1599$ & 9 & 2 & 4 & 1 \\
$1600-1604$ & 2 & 1 & & 2 \\
$1605-1610$ & 27 & 9 & 16 & 9 \\
Sumas & 121 & 52 & 60 & \\
\hline
\end{tabular}

Elaboración propia a partir de ASAY, $M$, vol. 1, 1567-1610.

Nota: se han sustraído las novias afros casadas con indígenas, a saber: tres en el intervalo de 1575-1579 y dos en el de 1595-1599.

Las cifras desagregadas de los quinquenios muestran que de 1575 a 1584 la participación de mujeres mayas en matrimonios con población negra fue significativa. Al revisar la información por años, se encuentra que de 1575 a 1582 hubo 24 matrimonios en los que participaron 19 mujeres indígenas, pero de 1579 a 1582 los enlaces fueron exclusivamente con ellas. En 1583 García de Palacio visitó la provincia en cuyo informe confirma las extracciones de muchachas sin edad ni "discreción" [léase criterio] para decidir las implicaciones del matrimonio con un esclavo, así como también la presencia de mujeres indígenas retenidas 
contra su voluntad, o la de sus maridos si eran casadas. Durante su estancia en Yucatán, el visitador persiguió amancebamientos pero, ¿ ¿cuántos encontró entre negros e indígenas en casas españolas? En realidad, García de Palacio registró solo el caso de Ximón, esclavo de Juan Dorado Ramírez, amancebado con la indígena casada Juana $\mathrm{Ta}$ (Pedernal), ${ }^{63}$ que "parió un mulato" hijo suyo y tenían vida maridable en la vivienda de su encomendero Diego López de Recalde, cuñado del amo de Ximón. ${ }^{64}$

Los registros parroquiales sugieren que las denuncias, recomendaciones civiles y la actuación del visitador frenaron los matrimonios afromayas durante cinco años, de 1583 a 1587, pero a partir de 1588 se reanudaron con cierto balance entre las mujeres afros y mayas, hasta que entre 1605 y 1610, de las 25 novias con calidades asignadas, 16 fueron indias y solo 9 afros. Ya para principios del siglo XVII, las cifras apuntan hacia el relajamiento de las presiones para impedir los enlaces mixtos.

Con un poco más de detenimiento veamos los casos de los matrimonios afroindígenas que causaron inquietud en las autoridades provinciales y los defensores de indios. Para ello es preciso identificar el estatus de los contrayentes, como ya explicamos, los esclavos, por lo general, son identificados como negros, y aquellos con el genitivo de fueron esclavos. ${ }^{65}$ Entre los desposados 51 eran esclavos, 26 criados y 37 libres; por su parte, entre las parejas se identificaron a 13 esclavas, 22 criadas, 15 libres y 4 hijas de varón esclavo. A diferencia de los esclavos, que duplicaban el número de criados, entre las novias se invierte la proporción, pero entre los hombres $31 \%$ eran libres, mientras que entre las mujeres solo lo eran 26 por ciento.

${ }^{63}$ Ese fue uno de los cargos sentenciados contra Diego López de Recalde. Ortiz Yam y Quezada (eds.), Visita de Diego García, p. 167.

${ }^{64}$ Declaración de Pedro Ucán, Tizimín, 19 de noviembre de 1583, en OrTiz Yam y Quezada (eds.), Visita de Diego García, pp. 143-145.

${ }_{65}$ Véase la discusión de estas fórmulas en los asientos eclesiásticos, en CAMPOS García, “Esclavitud”, p. 28. 


\section{Gráfica 1}

MUJERES CONTRAYENTES CON AFRO, 1575-1582

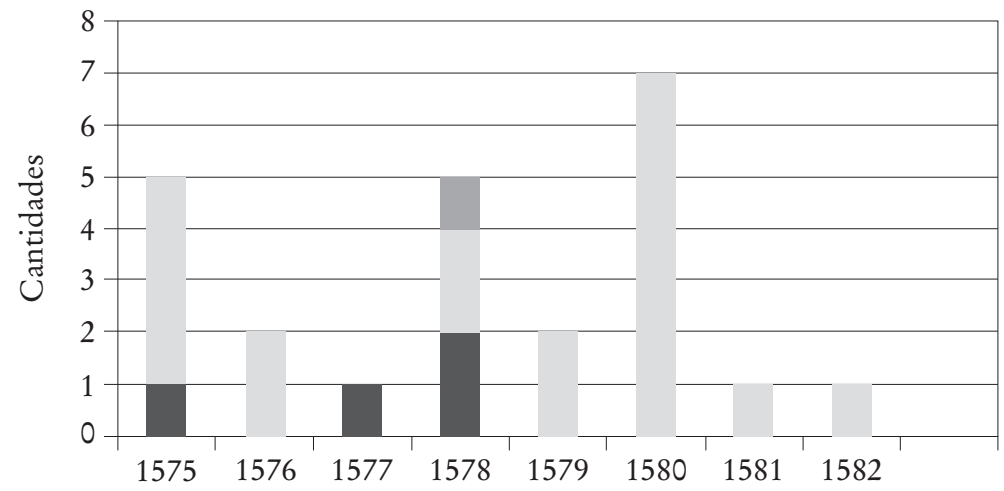

- Mujeres afro Mujeres mayas $\square$ Sin identificación racial

Tabla 3

MATRIMONIOS AFROINDÍGENAS, 1567-1610

\begin{tabular}{lrcccc}
\hline Quinquenios & $E-I$ & $M u-I$ & $M o-I$ & $N-I$ & Total \\
\hline $1565-1569$ & 5 & & & & 5 \\
$1570-1574$ & 5 & & & & 5 \\
$1575-1579$ & 8 & 1 & 1 & 1 & 10 \\
$1580-1584$ & 7 & 1 & & & 2 \\
$1585-1589$ & & 2 & & & 9 \\
$1590-1594$ & & 6 & 3 & 1 & 4 \\
$1595-1599$ & & 3 & & & \\
$1600-1604$ & 4 & 4 & 6 & 2 & 16 \\
$1605-1609$ & 29 & 17 & 10 & 4 & 60 \\
Sumas & & &
\end{tabular}

Nota: elaboración propia a partir de ASAY, $M$, vol. 1, 1567-1610.

Abreviaturas: $\mathrm{E}=$ esclavo, $\mathrm{Mu}=$ mulato, $\mathrm{Mo}=$ moreno, $\mathrm{N}=$ negro, $\mathrm{I}=$ mujer indígena.

Los registros parecen demostrar que en 1581 hubo una suspensión de los matrimonios de esclavos con mujeres indígenas, acatando las disposiciones de la corona, sin transgredir la política de excluir a los africanos esclavos y a los negros libres 
del mestizaje con mujeres indígenas. Pero de 1583 a 1608, en 25 años, hubo 13 matrimonios de 12 esclavos y un negro, al parecer libre, con igual número de parejas afros: nueve esclavas, tres mulatas y una sin etiqueta étnica, pero afrodescendiente. Un número de matrimonios de esclavos muy por debajo de los celebrados con mujeres indígenas en décadas anteriores. A partir de 1582 y hasta 1605 desaparecieron los registros de contrayentes esclavos o libertos, dando lugar a matrimonios de afromestizos con mujeres indígenas, es decir, con aquellos que ya habían pasado por una mixtura anterior con indígenas.

Tabla 4

ESPOSAS DE ESCLAVOS, 1583-1608

\begin{tabular}{cccc}
\hline Años & Esclavas & Mulatas & Hija de afro \\
\hline 1583 & 1 & - & - \\
1585 & 1 & - & - \\
1586 & - & 1 & - \\
1589 & - & 1 & - \\
1592 & 3 & - & - \\
1595 & 1 & - & - \\
1606 & - & 1 & - \\
1607 & 3 & - & - \\
1607 & 2 & - & - \\
1608 & - & - & 1 \\
\hline
\end{tabular}

En esas dos décadas continuó la llegada de esclavos a la provincia, aunque algunos ya casados; por ejemplo, en el inventario de bienes del difunto comerciante Francisco Figueroa, con calidad de residente, levantado el 31 de marzo de 1599, se registró un matrimonio esclavo entre Joan Bautista, "de tierra San Tomé”, de 40 años, y Esperanza Bautista, "de tierra Angola”, de 30 años, sin hijos; ${ }^{66}$ casos como el anterior no explican la ausencia de matrimonios de esclavos con mujeres mayas por 23 años.

${ }_{66}$ Después del fallecimiento de Figueroa, el matrimonio esclavo fue comprado por Diego de Bárcena en Mérida. AGI, C, leg. 328, ff. 37, 57v., 84-84v. 
No parece viable la transgresión y ocultamiento de matrimonios de esclavos mimetizados bajo la etiqueta de mulatos o morenos, con la omisión de violar la práctica de indicar el estatus jurídico del contrayente. Los tres asientos siguientes dan cuenta de ese tipo de registros:

- 1585, Blas Hernández moreno y Leonor de Bracamonte morena, ambos esclavos de Bartolomé García;

- 1588, Juan Pérez mulato horro y Francisca Yma; y

- 1609, Mateo de Durán moreno con Margarita morena, ambos "esclavos de Benito Durán”. ${ }^{67}$

Como se advierte en dichos asientos, son nupcias entre hijos e hijas de esclavas, por el uso de identificadores de moreno o mulato, en lugar del término negro asignado a los procedentes de África, de manera que la indicación "esclavo(s) de" revela claramente su estatus. Incluso en el caso del mulato Juan Pérez se establece que era horro, por lo tanto, se encontraba comprando su libertad mediante el sistema de ahorrado.

Las disposiciones reales de protección a las mujeres indígenas las prevenía de los matrimonios o convivencia con africanos de reciente arribo a la colonia, generalmente como esclavos; prohibición fundada en concepciones prejuiciadas de su cultura, que pondría en riesgo la evangelización, pero fundamentalmente, para librarlas del cautiverio al que estaban sujetos los esclavos. De modo que, sin descartar la posibilidad de que algún asiento bajo el registro de mulato o moreno con mujer indígena ocultara la condición de esclavo, el prolongado periodo de ausencia de enlaces de esclavos o negros con indígenas conduce a presentar la hipótesis de que los amos y el clero, al intervenir, propiciaron matrimonios entre los miembros del grupo negro y sus descendientes, con la resultante de permitir otras relaciones de convivencia; incluso cabe establecer la hipótesis alternativa

67 ASAY, $M$, vol. 1, 1567-1610, s. n. 
de que la preferencia por una pareja del mismo grupo étnico se acentuó en la medida del crecimiento de la población africana y los afrodescendientes.

¿Cuáles fueron los grupos culturales o étnicos de los africanos que se casaron con mujeres mayas? Por lo regular los registros carecen de algún término que ayude a identificar la procedencia de los africanos en Mérida. La tendencia fue borrar esas identidades por la genérica y colonialista de negros. No obstante esa práctica y limitación de la fuente, encontramos una muestra de 31 personas con referencias claras de su procedencia étnica.

\section{Tabla 5}

PROCEDENCIA ÉTNICA DE UN GRUPO DE AFRICANOS EN MÉRIDA, SIGLO XVI

\begin{tabular}{lll}
\hline $\begin{array}{l}\text { Número de } \\
\text { individuos }\end{array}$ & Identificador & Procedencia \\
\hline 7 & Biafra & Cabo Verde (Senegal y Sierra Leona) \\
6 & Zape & Zapés o Capé, tribu Kpwesi \\
1 & Cazanga & Casamancia, este de Sierra Leona \\
1 & Gallima & Gallina, Krim Vaia, Mandinga, Sierra Leona \\
7 & Angola & Genérico de las tribus de Angola \\
1 & Congo & Genérico de las tribus del Río Congo \\
2 & Lucumí & Yoruba \\
5 & Bannon & Bañol, pueblo Bagnon, Guinea Bissau \\
1 & Zolof & Jolof, wolof; Senegal, Guinea Bissau \\
\hline
\end{tabular}

Fuente: Aguirre BeLtrán, La población, pp. 99-150.

De este grupo de personas procedentes de la costa occidental de África, encontramos tres enlaces de Bannon con mujeres mayas, $\mathrm{y}$ también encontramos a dos angolas.

\section{CASAS ESPAÑOLAS Y MATRIMONIOS AFROMAYAS}

La población africana y sus descendientes en los hogaresvivienda de los españoles estaba asociada al estatus y a la 
economía de sus amos, en particular, entre autoridades administrativas y eclesiásticas, notarios, encomenderos y comerciantes, encontrándose una mayor presencia de servidumbre negra entre la élite encomendera y comerciante, así como entre notarios y escribanos. De acuerdo con nuestras indagaciones, si bien en dichas moradas concurría una extensa y pluriétnica servidumbre doméstica, existía una clara distinción entre a quién pertenecían y a quién ofrecían sus servicios. En la casa de Alonso de Rojas y Leonor Toro identificamos seis esclavos; cuatro sirvientes negros en las de Diego de Santillán y Beatriz de Montejo, y también en la de Hernando Muñoz Zapata y Ana Quixada; tres en la de Diego de Quixada y su esposa Guiomar de Acevedo, así como en la de Luis de Santa Cruz. ${ }^{68}$ Entre la servidumbre cohabitante en aquellas unidades domésticas en la Mérida del siglo Xvi, encontramos diversos tipos de uniones y mestizaje. Veamos algunos indicios de las complejas redes familiares domésticas.

Existen suficientes indicios para asegurar que hubo mayor densidad negra en las viviendas de la élite encomendera comerciante de Mérida en función de la riqueza económica, como lo demuestra el testamento de Martín de Palomar otorgado el 31 de diciembre de 1611, poco antes de morir. El capitán Palomar se casó en sus últimas horas de vida con Beatriz Bracamonte, por lo que puede presumirse que hasta ese momento estuvieron en concubinato. ${ }^{69}$ Su testamento ofrece la oportunidad de reconstruir la diversidad étnica y la composición de los grupos domésticos de la élite encomendera, comerciante y financiera.

${ }^{68}$ Campos García, “Esclavitud”, pp. 30, 32 y 38.

${ }^{69}$ Véase el estudio y la publicación del testamento en Patrón SARTi y GonzÁlez GonZÁlez, "El capitán Martín de Palomar". 
Tabla 6

COMPOSICIÓN ÉTNICA Y FAMILIAR

DE LA CASA DE MARTÍN PALOMAR

\begin{tabular}{|c|c|}
\hline Servidumbre indígena & Servidumbre negra \\
\hline $\begin{array}{l}\text { María Zulu (Sulub, esposa de Juan, } \\
\text { esclavo, casados en 1594) }\end{array}$ & $\begin{array}{l}\text { Juan, esclavo viejo y sus hijos con } \\
\text { Sulub: } \\
\text { Juana (mulata), Joaquín y otro de } \\
\text { corta edad }\end{array}$ \\
\hline \multicolumn{2}{|l|}{$\begin{array}{l}\text { Agustín Cauich y María Cen, } \\
\text { casados en } 1595\end{array}$} \\
\hline $\begin{array}{l}\text { Magdalena Chan (esposa de Manuel, } \\
\text { esclavo, casados en 1608) }\end{array}$ & Manuel, esclavo \\
\hline María Mex y su hija ${ }^{70}$ & $\begin{array}{l}\text { Constanza, esclava, madre soltera } \\
\text { Sus hijas: Leonor y María, esclavas }\end{array}$ \\
\hline Madalenilla & Juan, esclavo viejo \\
\hline María Vaz (Baas) & Agustín, esclavo \\
\hline Bernardinilla & Manuel, esclavo \\
\hline \multicolumn{2}{|l|}{ Sin mención de dependencia: } \\
\hline \multicolumn{2}{|l|}{ Andrea Canul, india } \\
\hline \multicolumn{2}{|l|}{ Ana Mex, india } \\
\hline \multicolumn{2}{|l|}{ Inés Chan, india } \\
\hline \multicolumn{2}{|l|}{ Francisca Chan, india } \\
\hline $\begin{array}{l}\text { María Na, "muchacha mestiza que } \\
\text { está en casa" }\end{array}$ & \\
\hline
\end{tabular}

Elaboración propia a partir de Testamento de Martín de Palomar, en PATrón SARTi y González GonzÁlez, "El capitán Martín de Palomar”, pp. 208-243; y ASAY, $M$, vol. 1, 1567-1610, s. n.

En la relación de beneficiarios de Palomar llama la atención María Na, “mestiza”, “que está en casa”, sobrina de la esclava

${ }^{70}$ El 21 de septiembre de 1608 fue bautizada María, hija de María, criada de Martín Palomar. ASAY, B, vol. 1, 1543-1617, f. 118.

${ }^{71}$ Es muy probable que tuviera una hija de corta edad, ya que el 10 de octubre de 1609 fue asentado el bautismo de María, hija de María Na, sin mayores detalles. ASAY, $B$, vol. 1, 1543-1617, f. 121. 
Leonor, lo que indica que es hija de una relación mixta de una hermana o hermano con indígena; y la asignación de una fuerte cantidad de dinero a Inés de Cabrera por sus servicios y por criar a una niña mulata llamada María de Castañeda.

El grupo doméstico de Martín de Palomar estaba constituido por 25 personas entre la servidumbre y las mujeres mencionadas sin una relación específica de subordinación: 12 indias, un indio, ocho esclavos (cinco hombres y tres mujeres), tres afromayas libres y una [afro]mestiza libre. En el grupo residencial cohabitaban seis núcleos familiares. Cuatro biparentales: 1) la convivencia conyugal Palomar-Bracamonte, 2) un matrimonio indígena sin descendencia, y 3 ) dos matrimonios esclavos mayas, uno con hijos y otro sin descendencia. Y dos monoparentales: 1) de mujer esclava con dos hijas también esclavas, y 2) de mujer indígena con una hija. Entre las mujeres encontramos a 11 solteras o muchachas (siete indígenas y una afromestiza, además de tres negras); y tres solteros esclavos. Entre población indígena domina el apellido Chan en tres mujeres: Magdalena, esposa del esclavo Manuel, y en dos mujeres de nombres Inés y Francisca, sin identificar la relación de parentesco entre ellas, si eran hermanas o hijas de Magdalena. El abanico de uniones maritales también se encuentra representado en ese núcleo doméstico: concubinato, matrimonios interétnicos y madres solteras.

En otro caso, el de Diego de Jáuregui, encomendero y comerciante, casado con Francisca Rosado, sin descendencia, la composición doméstica era muy distinta a la anterior. El grupo africano en casa de Jáuregui estaba integrado por 11 esclavos (seis varones y cinco mujeres), dos familias monoparentales con hijos esclavos de las que podemos suponer una relación de Lucrecia con un hombre maya, cuyo hijo Pedro fue identificado como "mulato", pero los demás hijos de ella y de María son identificados como "negros", un término que puede indicar padre africano.

Aunque los registros de bautismos de las parroquias de indios y negros para el periodo de nuestro estudio no se conservan, en 
Tabla 7

ESCLAVOS EN CASA DE JÁUREGUI

\begin{tabular}{|c|c|c|c|}
\hline Nombres & Edades & Hijos & Edades \\
\hline \multirow{3}{*}{ María, negra } & \multirow{3}{*}{30} & Diego, "negrillo" & 6 \\
\hline & & María, negra & 2.5 \\
\hline & & Juan, negro & 1 \\
\hline \multirow[t]{2}{*}{ Lucrecia, negra } & \multirow[t]{2}{*}{40} & $\begin{array}{l}\text { Pedro, negro (esclavo), } \\
\text { "mulato" }\end{array}$ & 12 \\
\hline & & Simón, negro & 2.5 \\
\hline Solteros & Edades & Solteros & Edades \\
\hline Antonio, negro & 36 & Pedro, negro & 26 \\
\hline Victoria, negra & 10 & Susana, negra & (?) \\
\hline
\end{tabular}

Elaboración propia a partir de Inventario de bienes, Mérida, 18 de septiembre de 1626, AGI, C, leg. 415, ff. 53-53v.

los asientos de la población española es posible encontrar algunos indicios de madres solteras y concubinatos que explicarían, en parte, la ausencia de matrimonios de esclavos con mujeres mayas. Veamos algunos indicios de la coexistencia de relaciones legales y de las consideradas ilícitas. En la casa Rojas-Toro dos de sus criadas fueron madres solteras, una en 1585 y otra en $1592 .{ }^{72}$ Beatriz Briena, criada de Alonso Gillán, tuvo un hijo llamado Francisco. ${ }^{73}$ En concubinato encontramos a Juan Román y Beatriz, “de color morena”, con una hija que asentaron como María, quien recibió el sacramento bautismal el 21 de noviembre de $1568 .{ }^{74}$ Y Francisca Xixona, mulata libre, fue madre soltera de Agustina, bautizada el 15 de octubre de 1598, con padrinos de estatus, el alcalde ordinario Francisco de Magaña y su esposa Francisca Chávez. ${ }^{75}$

72 ASAY, B, vol. 1, 1543-1617, ff. 59v., 82. Los asientos corresponden a Bernardina, hija de María de la Cruz, criada, del 27 de abril de 1585, y de Juan, hijo de Isabel López, soltera, moza, del 23 de septiembre de 1592.

73 ASAY, $B$, vol. 1, 1543-1617, f. 83.

74 ASAY, $B$, vol. 1, 1543-1617, f. 22v.

75 ASAY, $B$, vol. 1, 1543-1617, f. 96v. 
Los casos de Palomar y Jáuregui demuestran también que la suerte de las familias africanas y afromayas después de la muerte de sus amos dependía de sus propias mentalidades cristianas e intereses mercantilistas. Las evidencias en las comunidades domésticas de Figueroa y los dos antes mencionados, que compartían la característica de no dejar descendencia, sugieren que a la muerte del amo se dispersaba el grupo doméstico por liberar a sus esclavos, o disponer su venta y continuar bajo el signo de la esclavitud en otro espacio doméstico, no siempre desconocido. ¿Cómo se realizaron las ventas de los esclavos de aquellos encomenderos y comerciantes? La viuda de Figueroa vendió al matrimonio Bautista en 650 pesos. ${ }^{76}$ Palomar liberó a Juan, esposo de Sulub, y a Constanza con sus hijas, pero no a los solteros Manuel y Agustín, que fueron vendidos, en tanto que Jáuregui mandó que todas sus "mercaderías que se hallan en mi casa y [11] esclavos" fueran vendidos, con excepción de Susana que envió como esclava de una niña llamada María que estaba criando su suegro "en su casa". ${ }^{77}$ La viuda de Jáuregui vendió a Pedro, "mulato", hijo de Lucrecia, a un tratante de Tabasco, separándolo de su madre a la edad de 12 años. Asimismo, el otro Pedro, esclavo de 26 años, lo adjudicó a Juan Ortiz, vecino de Mérida. Pero los restantes ocho individuos fueron vendidos en grupo por un valor de 1180 pesos. ${ }^{78}$ De manera que los esclavos vendidos a otros amos de la ciudad podrían mantener, acaso expandir, sus redes de parentesco y familiaridad con quienes habían cohabitado durante la vida del patrón y en sus nuevas unidades de cautiverio.

De regreso a los matrimonios toca analizar si los amos españoles promovían o concertaban los matrimonios entre esclavos e indígenas con el afán de tener mayor personal a su servicio.

\footnotetext{
76 El matrimonio esclavo fue comprado por Diego de Bárcena en Mérida. AGI, C, leg. 328, ff. 84-84v.

77 AGI, C, leg. 415, ff. 43-43v., 143v.

78 AGI, C, leg. 415, f. 127.
} 
En los enlaces celebrados entre 1563 y 1610, entre los padrinos y testigos se advierten uniones de miembros de diferentes orígenes y condiciones, tanto endogámicos como exogámicos a los hogares-vivienda de los amos de los contrayentes. Del conjunto de matrimonios identificados hubo 8 casos de un mismo amo y 7 uniones exogámicas, pero en el conjunto de testigos o padrinos encontramos un número mayor de matrimonios entre esclavos de un mismo dueño, con 11 casos. Por lo tanto, no hay una clara indicación de que los amos hubieran forzado matrimonios entre sus esclavos y sus criadas indígenas; la tendencia era propiciar la endogamia, sin ser privativo de alguna calidad en particular. Casaban entre sí a naboríos, indígenas, negros, esclavos y criados afrodescendientes para mantener e incrementar el arraigo y prestigio de los amos españoles.

Don Carlos de Arellano casó a su esclavo Felipe con una indígena de Conkal en 1568 y a su criado Juan Xochimilco, mexica, con su criada Juana, mulata, en 1575. Pero Catalina, esclava de la viuda de Godínez, se casó con el esclavo de Juan Orduña. Cuando un amo tenía un esclavo (o criado negro) y una esclava (o criada negra) por lo general contraían matrimonio, como en los casos de Benito Durán, Luis de Santa Cruz, Diego de Segovia; así como observamos en otros amos con más posesiones, por ejemplo, Melchor Pacheco, quien, de sus tres esclavos hombres, uno estaba casado con una de sus esclavas y dos con mujeres indígenas, aunque sin precisar la relación de éstas con Pacheco. El obispo Francisco Toral casó a sus criados morenos Cecilia y Antonio Rodríguez en 1570, y a su vez Martín de Palomar, quien como defensor de los indígenas se quejó contra los encomenderos por casar a sus esclavos negros con indígenas, unió a dos de sus criados morenos con indígenas y a una pareja de naboríos.

A pesar del periodo de restricción para matrimonios de negros y esclavos con indígenas, según el modelo de Trento la preferencia de esclavos, negros, o africanos de reciente arribo con 
indígenas sugiere la disposición de los africanos y las mayas para el matrimonio mixto, más que la de hombres indígenas con africanas. La tendencia observable entre los propietarios fue propiciar que sus esclavas contrajeran nupcias con sus propios esclavos, en menor medida con criados afromestizos y raramente con hombres indígenas. La endogamia doméstica entre esclavo y esclava fue más visible en los años ochenta del siglo Xvi, es decir, cuando se endureció la oposición a los casamientos entre (negros) esclavos y mujeres mayas. En general, sobre el conjunto de matrimonios negros en la Mérida del siglo xvi, por la mentalidad y normas católicas de vida, los encomenderos y oficiales de la administración colonial y religiosa preferían que los afros tuvieran relaciones estables consagradas por la Iglesia y el Estado que las uniones transitorias e itinerantes, o amancebamientos.

\section{LAS PREFERENCIAS MATRIMONIALES \\ DE LOS MULATOS DE LA TIERRA}

El mestizaje africano maya vinculado con el estatus de cautivo o libre trajo consigo algunas identificaciones ambiguas de la descendencia. En una cita a los alegatos de Palomino dejamos para este apartado subrayar el término "castas” para identificar a la descendencia afroindígena, en tanto que en los registros matrimoniales encontramos asientos peculiares: "negro mulato" y "negro moreno". El 21 de febrero de 1591, el provisor Marcos de Segura, cura de la Catedral, casó a Marcos Monte "negro mulato" con Catalina May india. ${ }^{79}$ Ese mismo año, el 14 de julio, el mismo cura, en el matrimonio de Francisco mulato con Inés indígena del pueblo extramuros de San Cristóbal, vuelve a aparecer Marcos Monte como "negro mulato", pero se identificó como criado de Juan de la Cámara. ${ }^{80} \mathrm{La}$ asociación de términos

\footnotetext{
79 ASAY, $M$, vol. 1, 1567-1610, f. 162v.

80 ASAY, $M$, vol. 1, 1567-1610, f. 163.
} 
"negro mulato" es ambigua, pero identifica a los nacidos en la tierra, producto del afromestizaje. En ese mismo sentido se encuentra el caso de Roque "negro moreno" de oficio espadero, quien fungió como testigo en una boda del 21 de mayo de $1578 .{ }^{81}$

Pero lo más destacable en la Mérida del siglo xvi fue el término mulato con una connotación local para designar a los hijos de los matrimonios afromayas, ${ }^{82}$ como lo confirman los siguientes asientos:

1578. Melchiora de Campos mulata, hija de Baltazar Hernández mulato y Mencia indígena.

1590. Baltazar de Ribera mulato, hijo de Juan de Ribera mulato y María Pech.

1591. Diego Rodríguez mulato, hijo de Juan Zape [africano $]^{83}$ y Ana Chan.

1592. Isabel y Ana mulatas, hijas de Domingo de Tamayo [africano] y Ana india.

1604. Juana mulata, hija de Anjón Biafra [africano] y María Chan; y, por último,

1608. Pedro moreno, hijo de Juan moreno e Inés Pol.

\footnotetext{
${ }^{81}$ ASAY, $M$, vol. 1, 1567-1610, s. n. En Puebla el término "negro criollo" indicaba a los negros nacidos en aquella localidad para distinguirlos de los bozales, o recién arribados a la tierra. En el siglo xviı, el término mulato aludía a hijos de blancos con esclavas, como era el sentido más generalizado, pero en algunos casos se describía como mulato a un individuo blanco. CASTILLO, "La pérdida", pp. 302-303, 305.

${ }_{82}$ Ya no se sostiene la idea de que en Yucatán el término mulato era de uso muy raro, sino que lo más común fue pardo, como aseveró EsPejo-Ponce DE Hunt, "Colonial Yucatan", p. 96; y a pesar de algunas evidencias del uso de "color pardo" en la ciudad de Mérida, como advierten Victoria Ojeda y SÁNCHEz, "Interetnicidad”, p. 26, nota 85, la tendencia decantó hacia forjar la identidad de mulato, en lugar del pardo de los siglos posteriores.

${ }^{83}$ En ocasiones la identidad racial asignada al padre se omitía pero claramente su origen era africano, en otras se omitía la etnia de la madre, cosa muy reconocible por el apellido maya que prevalecía. El problema mayor se encuentra entre las mujeres y hombres que tenían nombres y apellidos españoles y que eran indígenas o afros.
} 
Estos asientos sugieren que con el término mulato se identificaba a la prole de matrimonios mixtos entre negros o afromestizos con mujeres mayas, etiqueta que heredaban del padre; en cambio el término moreno fue de uso muy reducido entre aquella descendencia. Este descubrimiento nos permite concluir que el mulato fue una categoría racial utilizada en la Mérida del siglo xvi para identificar a descendientes de africanos e indígenas mayas, antes del uso generalizado del término pardo durante el siglo XviII. El amulatamiento como etiqueta para identificar a la población afromestiza en Mérida fue anterior a su apardamiento.

En efecto, entre 1585 y 1610 hubo cerca de 25 novias mulatas, muchas de ellas afromayas. Incluso, los hijos de negros con estatus de personas libres y privilegios de español se casaron con afros de reciente arribo en la ciudad y con cierto estatus. En cinco de seis casos que hemos identificado de dos generaciones de matrimonios afros, se observa que de aquellas uniones de negros, mulatos y morenos con mujeres mayas, a fines de la década de 1580 , sus hijos "mulatos" no se casaron con indígenas, sino con mulatas o morenas, es decir, con parejas de su propio grupo étnico; solo en un caso un descendiente mulato contrajo nupcias con una mujer indígena (véase el apéndice). En otro enlace por demás significativo por la trayectoria del padre africano en tierras de Yucatán, el 6 de agosto de 1588 se casó Antonia Toral, hija de Sebastián Toral y Cecilia Toral, con Simón de Montesinos hijo de Luis Díaz y Lucía Chesaria. ${ }^{84}$ En ningún caso se puso alguna etiqueta racial por el estatus del padre de la novia, tampoco al novio ni a sus padres, pero resulta que su madre solo fue asentada con sus nombres, Lucía Chesaria, seguidos de su procedencia: "de las Islas de la Gomera", por lo que se tienen tres posibilidades acerca de su identidad étnica: 1) que fuese una "esclava blanca" de aquella isla, cuya población fue reducida a la esclavitud a fines del siglo xv y muchos de ellos fueron enviados

${ }_{84}$ ASAY, $M$, vol. 1, 1567-1610, f. 154. 
a las nuevas tierras descubiertas y conquistadas, ${ }^{85}$ 2) que fuese una esclava embarcada en aquella isla canaria y originaria de las costa de Mauritania, cuando el comercio de esclavos africanos se abrió en $1586,{ }^{86} \mathrm{o} 3$ ) que fuera persona libre.

La etiqueta de identificación personal de cada grupo socioracial reviste una diferenciación notable entre negros, esclavos y mulatos. Por lo general, los esclavos y negros fueron asentados con sus nombres sin apellidos; en ocasiones se advierte que poseen los apellidos de sus amos, o de sus primeros amos o, como señalamos arriba, el nombre era acompañado con su lugar de origen: Angola, Congo, etcétera (véase la tabla 5). Ese fue el mismo comportamiento de la administración eclesiástica en los asientos de matrimonio de morenos, que fungían como eufemismo de negro. Pero entre los mulatos las cosas fueron distintas. En los asientos de matrimonios, como padrinos o testigos, era muy raro que los mulatos no fueran registrados con nombre y apellido español, en algunas ocasiones seguido del dato de que fueran criados o esclavos, entendiéndose que sin esta precisión de su condición de sujeción, los mulatos eran libres.

\section{PADRINAZGO NEGRO, TESTIGOS Y REDES FAMILIARES}

Los lazos de parentesco no solo se establecieron a partir de los matrimonios consentidos o propiciados en esos ámbitos domésticos de la ciudad en construcción, sino también por el parentesco ritual entre los contrayentes, testigos y padrinos de la ceremonia eclesiástica. Como ya estudiamos en un primer apartado, la práctica colonial del arrebato por consentimiento pobló las casas españolas de huérfanas, viudas y niñas. Las indígenas casadas con esclavos en ocasiones perdían sus vínculos familiares - quizá

85 Aguirre Beltrán, La población, pp. 105-106.

${ }^{86}$ De 1586 a 1590, la corona autorizó seis embarques de esclavos desde las islas Canarias, y 14 entre 1591 y 1600. Curtin, The Atlantic Slave Trade, pp. 103-105. 
por ser desarraigadas -, mientras que recibían todo el soporte de la red doméstica de los esclavos. En el caso del matrimonio celebrado el 18 de abril de 1575 entre Sebastián, negro esclavo y Ana Chan, indígena, sus padrinos fueron Juan Biafra, negro e Isabel negra, y los testigos Fernando, negro y Juan Congo, todos ellos, el novio, los padrinos y los testigos, esclavos que pertenecían al grupo doméstico de Hernando de San Martín. ${ }^{87}$ Incluso con las presiones para impedir los matrimonios afromayas, los contrayentes negros (esclavos) con mujeres indígenas tuvieron padrinos negros y en menor medida matrimonios mixtos. El cuadro 1 relaciona una muestra de 17 parejas enlazadas entre 1578 y 1608, donde se observa la presencia de familiares mayas de la novia entre los testigos del enlace, una especie de continuidad del consentimiento de un ascendiente, familiar o conocido indígena de la misma población de origen.

\section{Cuadro 1}

PADRINAZGO NEGRO Y RELACIONES DOMÉSTICAS

\begin{tabular}{|c|c|c|c|}
\hline Año & Casa de & Matrimonios & Padrinos/Testigos \\
\hline \multirow[t]{2}{*}{1578} & $\begin{array}{l}\text { Francisco } \\
\text { Arceo }\end{array}$ & $\begin{array}{l}\text { Andrés } \\
\text { Cecilia, mulata }\end{array}$ & $\begin{array}{l}\text { Francisco, esclavo de Martín Sánchez, } \\
\text { su esposa Catalina Ucán }\end{array}$ \\
\hline & $\begin{array}{l}\text { Francisco } \\
\text { Arceo }\end{array}$ & $\begin{array}{l}\text { Melchor Dzab, criado } \\
\text { Leonor, criada }\end{array}$ & $\begin{array}{l}\text { Francisco García, negro } \\
\text { Juana, negra esclava de Francisco Arceo }\end{array}$ \\
\hline 1580 & $\begin{array}{l}\text { "Rojas- } \\
\text { Toro" }\end{array}$ & $\begin{array}{l}\text { Melchior Quiatit } \\
\text { Ana Chablé de Conkal }\end{array}$ & $\begin{array}{l}\text { Francisco, mulato } \\
\text { I Francisca, mulata, ambos de la misma casa }\end{array}$ \\
\hline 1581 & $\begin{array}{l}\text { "Rojas- } \\
\text { Toro" }\end{array}$ & $\begin{array}{l}\text { Juan, esclavo } \\
\text { Fabiana, esclava }\end{array}$ & $\begin{array}{l}\text { María Kú, criada de la misma casa } \\
\text { Agustín Ek, criado de Antón Cano }\end{array}$ \\
\hline 1592 & $\begin{array}{l}\text { "Rojas- } \\
\text { Toro" }\end{array}$ & $\begin{array}{l}\text { Agustín Chan, } \\
\text { Beatriz Chuc, criados }\end{array}$ & $\begin{array}{l}\text { Gabriel, sevillano mulato de Gómez de } \\
\text { Castrillo, y Catalina de Rojas, morena }\end{array}$ \\
\hline 1580 & $\begin{array}{l}\text { Juan de } \\
\text { Arbieto }\end{array}$ & $\begin{array}{l}\text { Melchior, mulato del } \\
\text { amo } \\
\text { Beatriz de Alvarado, } \\
\text { india }\end{array}$ & $\begin{array}{l}\text { Martin, negro del amo y Beatriz Poot su } \\
\text { mujer. } \\
\text { Testigos: Gabriel de Godínez, negro } \\
\text { De la novia su madre Mencia Canché y } \\
\text { Ana Hernández, mulata }\end{array}$ \\
\hline
\end{tabular}

${ }_{87}$ ASAY, $M$, vol. 1, 1567-1610, f. 109, asiento del 25 de abril de 1575. 


\begin{tabular}{|c|c|c|c|}
\hline$A \tilde{n} o$ & Casa de & Matrimonios & Padrinos/Testigos \\
\hline 1580 & $\begin{array}{l}\text { Melchor } \\
\text { Pacheco }\end{array}$ & $\begin{array}{l}\text { Diego Bueno, negro } \\
\text { María Chan }\end{array}$ & $\begin{array}{l}\text { Andrés, negro, y Juana, negra de Arceo. } \\
\text { Testigos: Andrés, negro de Arceo, Gaspar } \\
\text { Chan y Diego Poot de Hocabá }\end{array}$ \\
\hline 1580 & $\begin{array}{l}\text { Antón } \\
\text { Julián }\end{array}$ & $\begin{array}{l}\text { Antonio, negro del } \\
\text { amo } \\
\text { María Chable, criada } \\
\text { de Franisco Tamayo }\end{array}$ & $\begin{array}{l}\text { Mateo, negro del capitán portugués } \\
\text { Ana, negra del contador }\end{array}$ \\
\hline 1580 & $\begin{array}{l}\text { María de } \\
\text { Segura }\end{array}$ & $\begin{array}{l}\text { Juan, negro de la ama } \\
\text { María Xol, de } \\
\text { Hunucmá }\end{array}$ & $\begin{array}{l}\text { Antón y Catalina, negros } \\
\text { Testigos: Melchor, negro de Juan Orduña y } \\
\text { Juan, negro de Romero. De la novia fue } \\
\text { Francisco Matú, de Hunucmá }\end{array}$ \\
\hline 1580 & Deán & $\begin{array}{l}\text { Francisco, negro del } \\
\text { deán } \\
\text { María Cobá, india }\end{array}$ & $\begin{array}{l}\text { Manuel, criado de Bartolomé Pérez; y de } \\
\text { la novia, Juan Cobá y Pedro Chablé de } \\
\text { Chuburná. }\end{array}$ \\
\hline 1581 & $\begin{array}{l}\text { Bartolomé } \\
\text { Sánchez }\end{array}$ & $\begin{array}{l}\text { Domingo, mulato } \\
\text { criado del amo } \\
\text { María Chi, criada de } \\
\text { Lucas Moreno }\end{array}$ & $\begin{array}{l}\text { Constantín Rodriguez y Francisca } \\
\text { Rodríguez, su mujer. } \\
\text { Testigos: Diego, negro padre del novio; y } \\
\text { de ella, Alonso Pool }\end{array}$ \\
\hline 1590 & $\begin{array}{l}\text { Gerónimo } \\
\text { Castro }\end{array}$ & $\begin{array}{l}\text { Pedro Chin, del pueblo } \\
\text { de San Cristóbal } \\
\text { Catalina Euán, del } \\
\text { pueblo de San Juan }\end{array}$ & $\begin{array}{l}\text { Constantín, moreno } \\
\text { María, morena, criados en la misma casa }\end{array}$ \\
\hline 1590 & Sin vínculo & $\begin{array}{l}\text { Hernando Cutz } \\
\text { Catalina Chan, viuda, } \\
\text { Vecinos del pueblo de } \\
\text { Santa Lucía }\end{array}$ & $\begin{array}{l}\text { Pedro, moreno } \\
\text { Isabel, morena, ambos criados de Jhoan } \\
\text { Argaiz }\end{array}$ \\
\hline 1594 & $\begin{array}{l}\text { Martín de } \\
\text { Palomar }\end{array}$ & $\begin{array}{l}\text { Joan, moreno esclavo } \\
\text { María Sulub, criada }\end{array}$ & $\begin{array}{l}\text { Francisco Zape, moreno, y su esposa } \\
\text { María, ambos esclavos de Benito Díaz }\end{array}$ \\
\hline 1595 & $\begin{array}{l}\text { Martín de } \\
\text { Palomar }\end{array}$ & $\begin{array}{l}\text { Agustín Cauich, } \\
\text { María Cen, naboríos }\end{array}$ & $\begin{array}{l}\text { Juan Pérez, mulato, y Francisca Dzán, } \\
\text { naboríos de San Juan. } \\
\text { Testigos: Juan Bermúdez, alcalde (quizá del } \\
\text { pueblo) y Juan, moreno criado de Palomar }\end{array}$ \\
\hline 1608 & $\begin{array}{l}\text { Martín de } \\
\text { Palomar }\end{array}$ & $\begin{array}{l}\text { Manuel, moreno } \\
\text { Magdalena Chan, india }\end{array}$ & $\begin{array}{l}\text { Juan, moreno de Benito Díaz } \\
\text { Juan Biafra, moreno de Bernardo de Sosa }\end{array}$ \\
\hline 1598 & $\begin{array}{l}\text { Diego } \\
\text { Segovia }\end{array}$ & $\begin{array}{l}\text { Diego Kú, criado } \\
\text { Ana May, criada }\end{array}$ & $\begin{array}{l}\text { Andrés López } \\
\text { Francisca, ambos morenos criados del } \\
\text { mismo }\end{array}$ \\
\hline
\end{tabular}

Nota: elaboración propia a partir de la información de ASAY, $M$, vol. 1, 1567-1610. San Cristóbal, San Juan y Santa Lucía fueron pueblos indígenas extramuros de la ciudad de Mérida. 
Asimismo, esos arreglos conciliatorios demuestran la formación de nuevos tejidos familiares a partir de parentescos por afinidad, consanguinidad y rituales entre los desarraigados de la costa occidental de África y las indígenas extraídas de las comunidades mayas que echaron raíces en la etapa temprana de Mérida. El padrinazgo de bodas mantuvo la frontera étnica en el sentido de que los afros figuraron regularmente como padrinos y madrinas en 11 bodas afros y afromayas, y en cinco ocasiones fueron padrinos de nupcias indígenas, mientras que se observa la ausencia significativa de alguna pareja autóctona apadrinando algún matrimonio afro o mixto (véase el cuadro 1). Sin embargo, las parejas afromayas tuvieron presencia en bodas indígenas y afros como padrinos y madrinas casados o sin evidencia de ello en los asientos parroquiales. En aquellos años el padrinazgo negro fue de importancia incluso en matrimonios de alguna autoridad o principal indígena. Este fue el caso de Juan Xol, gobernador indígena del pueblo de Teya, quien contrajo nupcias con Isabel Chan el 25 de febrero de 1580 y ofició el deán de la Catedral; los padrinos fueron el maestro Pedro negro y su mujer Catalina, mientras que entre los testigos del novio estuvieron Juan Yam y Antón Xol, y por ella atestiguó Diego Chan de Caucel, posiblemente su hermano. ${ }^{88}$

La endogamia y exogamia domésticas también se expresaron entre los padrinos. En una ceremonia, acaso paradigmática de matrimonios entre parejas de un mismo grupo doméstico y padrinazgo negro, en 1598 contrajeron nupcias Diego Ku y Ana May, criados de Diego Segovia, cuyos padrinos fueron Andrés López y Francisca, morenos criados del mismo. En 1570 contrajeron nupcias los indígenas Francisco May y María Chuc, criados de Roque Álvarez, y sus padrinos fueron Roque negro y su mujer sin nombre ni raza, con la breve leyenda: "todos

${ }_{88}$ ASAY, $M$, vol. 1, 1567-1610, f. 125v. 
criados de Álvarez" ${ }^{89}$ En el matrimonio endogámico de Domingo y María Pisté, esclavo y criada de Juan Magaña en 1574, los padrinos fueron externos a la vivienda del amo, Francisco y Ana esclavos del contador Pedro Gómez. ${ }^{90}$ Pero en 1578 Francisco de Arceo celebró dos bodas, una de un esclavo y otra de criados indígenas; en esta ocasión, el amo no casó a sus esclavos entre ellos, pero sí a sus indígenas criados; los padrinos de su esclavo fueron una pareja externa al hogar, pero en la boda de los criados indígenas la madrina fue del mismo (véase el cuadro 1).

Los amos en raras ocasiones apadrinaron matrimonios afros o mixtos, pero hubo sus excepciones significativas. Don Diego de Santillán y doña Andrea apadrinaron el matrimonio del reconocido Juan Xochimilco, mexica, con Juana mulata, ambos criados de don Carlos de Luna y Arellano en 1575. Y cuando dos años después Juan Cauich indio contrajo nupcias con Magdalena mulata, ambos criados de Santillán, los padrinos fueron Juan de Montejo y doña Isabel. Entre otros amos que apadrinaron matrimonios afros, no necesariamente de sus criados o esclavos, están Francisco Tamayo, doña Francisca mujer de Carlos de Arellano, Melchor de los Reyes, Juana de Vargas, Gerónimo de Castro y su mujer María Ordóñez.

En el naciente espacio urbano, el modelo ideal de casa poblada condujo a los españoles a incrementar el tamaño de su grupo familiar incluyendo la ampliación de la servidumbre ${ }^{91}$ mediante los matrimonios de sus criados (en sus dos acepciones), así como entre su servidumbre libre y cautiva. La expresión más contundente se encuentra en los asientos de la servidumbre de Alonso de Rojas y su esposa Leonor de Toro. El 23 de febrero de 1580 Melchor Quiatit “de casa de Rojas” se casó con Ana Chablé de Conkal; los testigos fueron: del primero su madre

\footnotetext{
${ }^{89}$ ASAY, $M$, vol. 1, 1567-1610, f. 105v., asiento del 26 de enero de 1570.

${ }^{9}$ ASAY, $M$, vol. 1, 1567-1610, f. 108v., asiento del 5 de diciembre de 1574 .

${ }^{91}$ Zamora, "Lo doméstico".
} 
María Dzib, y de la segunda su hermano Diego Chablé, y sus padrinos: Francisco mulato y Francisca mulata. ${ }^{92}$ Diez años después, el 8 de enero de 1592, contrajeron nupcias Agustín Chan y Beatriz Chuc, ambos indígenas "criados de Leonor de Toro", cuyos padrinos fueron Gabriel, sevillano mulato de Gómez de Castrillo y la morena Catalina de Rojas, y para que no existieran mayores dudas, el asiento ratificó la pertenencia con la siguiente inscripción: "Testigos de su libertad Leonor de Toro y sus criados porque nacieron y se criaron en su casa". ${ }^{93}$ A su vez, en 1581, los esclavos Juan y Fabiana de la casa Rojas-Toro apadrinaron el matrimonio de María Ku, criada de Rojas, con Agustín Ek, criado de Antón Cano.

Mediante la información contenida en los registros matrimoniales se tienen indicios de las relaciones de los contrayentes con padrinos y testigos pertenecientes a otros grupos domésticos o casas españolas (véase el cuadro 1). Las redes tejidas entre la servidumbre negra e indígena no se redujeron a las casas intramuros de la ciudad. En el caso de Agustín Cauich y María Cen, naboríos, matrimonio registrado en 1595, los apadrinó una pareja mulato indígena, "naboríos en [el pueblo extramuros de] San Juan", y sus testigos fueron Juan Bermúdez, alcalde posiblemente del mismo pueblo, y Juan moreno, criado de Palomar. Por último, el matrimonio celebrado el 24 de julio de 1589 da cuenta de la vecindad afromaya en el pueblo indígena de Santa Lucía, fundado hacia la década de 1570 , tres cuadras al norte de la plaza principal de Mérida. Ese día se casaron Hernando Cutz y la viuda Catalina Chan, ambos vecinos de Santa Lucía; sus testigos fueron vecinos del mismo pueblo, Pedro May y Moisés Cimá, pero los padrinos fueron Pedro moreno e Isabel morena de Jhoan Argaiz..$^{94}$ En otro caso, el 13 de junio de 1590,

\footnotetext{
${ }_{92}$ ASAY, $M$, vol. 1, 1567-1610, s. n.

${ }^{93}$ ASAY, $M$, vol. 1, 1567-1610, f. $164 \mathrm{v}$.

${ }^{94}$ ASAY, $M$, vol. 1, 1567-1610, f. 157.
} 
Constantín y María, morenos criados de Gerónimo de Castro, apadrinaron el casamiento de Pedro Chin y Catalina Euán, vecinos de los pueblos indígenas de San Cristóbal y San Juan, respectivamente. ${ }^{95}$

Las relaciones familiares dentro de las casas españolas y las externas establecidas mediante los matrimonios, los parentescos rituales y la participación de testigos externos al grupo doméstico demuestran la constitución de redes de parentesco que fueron extendiéndose a espacios extramuros de la ciudad de Mérida.

\section{CONCLUSIÓN}

Si la ciudad fue una fundación de conquistadores españoles (blancos), ya que por sus costumbres jurídicas les tocaba fundar comunidades políticas, la ciudad como colectivo humano fue constituida por españoles de diversas regiones, mesoamericanos (mayas y mexicas) y africanos de diferentes culturas de la costa atlántica de África, que a su vez por sus enlaces interétnicos formaron el conglomerado multiétnico de la Mérida del siglo xvI. Los desarraigados de sus tierras y redes de parentesco, los africanos y las mujeres mayas establecieron diversos tipos de familias a partir de matrimonios cristianos, de uniones señaladas como ilegítimas y de familias monoparentales. Antes del modelo de Trento las evidencias sugieren la poca importancia que le otorgaban al matrimonio cristiano, y fue ese modelo, combinado con las presiones civiles y del visitador García de Palacio (1583), que abrió el ámbito de las relaciones ilícitas. Los mulatos de la tierra, la progenie de los matrimonios afromayas, forzados o no por los amos, demostraron vitalidad con sus preferencias matrimoniales entre parejas del mismo grupo y con una discreta tendencia a la reafricanización, tomando distancia de la raíz autóctona.

${ }_{95}$ ASAY, $M$, vol. 1, 1567-1610, vol. 1, f. 160v. 
El conjunto de matrimonios afromayas con sus testigos y padrinos demuestra que si bien la población esclava habitaba en los patios posteriores de las casas españolas, como lo comprueba la convivencia residencial de los Rojas-Toro, Palomar, Jáuregui y Figueroa, lo cierto es que para fines del siglo xvi y principios del xvir, los africanos, los afrodescendientes y los matrimonios afromayas habían consolidado relaciones familiares con los naboríos y residentes extramuros, donde había iniciado un lento proceso de asentamiento afro. Fue entonces cuando, en 1612, la Iglesia abandonó el criterio de clasificación por clase naboría o trabajadora, sin distinción de negros e indígenas mesoamericanos, y se constituyó el curato de "castas mulatas (afromayas) y negras", con sus libros para registros de bautismos, matrimonios y defunciones, su propia capilla externa situada en el costado sureste de la Catedral con advocación al Santo Nombre de Jesús, ${ }^{96}$ y su propia cofradía. ${ }^{77}$ Había nacido una comunidad afromaya urbana con su propia parroquia separada de las otras calidades y sus propias instituciones de solidaridad.

\section{SIGLAS Y REFERENCIAS}

AGI, C Archivo General de Indias, Contratación, Sevilla, España.

AGI, I Archivo General de Indias, Indiferente, Sevilla, España.

AGI, $A M$ Archivo General de Indias, Audiencia de México, Sevilla, España.

AHN, DC Archivo Histórico Nacional, Diversas Colecciones, Madrid, España.

ASAY, $B$ Archivo de la Secretaría del Arzobispado de Yucatán, Bautismos, Mérida, México.

\footnotetext{
96 Para mayor información sobre el abandono del criterio de clase por el de casta, véase CAmpos García, “Esclavitud”, pp. 40-42.

97 Testamento de Martín de Palomar, Mérida, 31 de diciembre de 1611, en PATrón SARti y González González, “El capitán Martín de Palomar”, p. 211. Es posible que la cofradía de morenos fuera la del Santo Nombre de Jesús, en la que participaban "negros, mulatos y españoles"; y por supuesto, también morenos, como sugieren Victoria OJEDA y Sánchez, “Interetnicidad”, p. 17.
} 
ASAY, $M \quad$ Archivo de la Secretaría del Arzobispado de Yucatán, Matrimonios, Mérida, México.

Ancona, Eligio, Historia de Yucatán, Mérida, México, Ediciones de la Universidad Autónoma de Yucatán, 1978, vol. 2.

Aguirre Beltrán, Gonzalo, La población negra de México. Estudio etnohistórico, México, Fondo de Cultura Económica, 1972.

Andrés-Gallego, José, La esclavitud en la América española, Madrid, Ediciones Encuentro, Fundación Ignacio Larramendi, 2005.

Askinasy, Siegfried, El problema agrario de Yucatán, México, Ediciones Botas, 1936.

Bernand, Carmen, Negros esclavos y libres en las ciudades hispanoamericanas, Madrid, Fundación Ignacio Larramendi, 2000.

Calvo, Thomás, La Nueva Galicia en los siglos XVI y XVII, Guadalajara, El Colegio de Jalisco, Centro de Estudios Mexicanos y Centroamericanos, 1989.

CAmba Ludlow, Úrsula, Imaginarios ambignos, realidades contradictorias: conductas y representaciones de los negros y mulatos novohispanos. Siglos XVI y XVII, México, El Colegio de México, 2008.

Campos García, Melchor, "Esclavitud y servidumbre negra en la ciudad de Mérida, Yucatán: 1563-1610”, en Iberoamericana. América Latina-EspañaPortugal, xv: 58 (2015), pp. 21-44.

CÁrdenas y Romero, José Eduardo, Memoria a favor de Tabasco en la Nueva España (1811). Edición facsimilar preparada por Miguel Ángel Díaz Perera, Villahermosa, Grupo DG, El Colegio de la Frontera Sur, 2010.

CASTAÑEDA, Carmen, "La formación de la pareja y el matrimonio", en GonZALbo Aizpuru (coord.), 1991, pp. 73-99.

Castillo, Norma Angélica, "La pérdida de la población de origen africano en la región de Puebla. El cruce de la barrera del color por las inconsistencias de las categorías raciales. Análisis de las genealogías y conflictos interétnicos”, en Velázquez Gutiérrez y Correa Duró (comps.), 2005, pp. 299-325.

Cook, Sherburne F. y Woodrow BoraH, Ensayos sobre historia de la población: México y el Caribe, México, Siglo Veintiuno editores, 1978, 2 volúmenes. 
Cortés Jácome, María Elena, "Los ardides de los amos: la manipulación y la interferencia en la vida conyugal de sus esclavos. Siglos XVI-XVII", en GuZMán VÁzquez y Martínez O. (eds.), 1989, pp. 43-57.

Curtin, Philip D., The Atlantic Slave Trade. A Census, Madison, The University of Wisconsin Press, 1969.

Duncan, Quince, “¿Existen las razas?”, en Velázquez Gutiérrez y Correa DuRó (comps.), 2005, pp. 217-225.

Espejo-Ponce de Hunt, Marta, "Colonial Yucatan: Town and Region in the Seventeenth Century", tesis de doctorado en historia, Los Ángeles, University of California, 1974.

FARRISs, Nancy M., La sociedad maya bajo el dominio colonial. La empresa colectiva de la supervivencia, España, Alianza Editorial, 1992.

Fernández Repetto, Francisco y Genny Negroe Sierra, Una población perdida en la memoria: los negros de Yucatán, Mérida, México, Universidad Autónoma de Yucatán, 1995.

García González, Francisco, Familia y sociedad en Zacatecas. La vida de un microcosmos minero novohispano, 1750-1830, México, El Colegio de México, Universidad Autónoma de Zacatecas, 2000.

GHIRARDI, Mónica (coord.), Familias iberoamericanas ayer y hoy. Una mirada interdisciplinaria, Río de Janeiro, Asociación Latinoamericana de Población, 2008.

Gonzalbo Aizpuru, Pilar, "El orden de la familia en la Nueva España”, en GHIRARDI (coord.), 2008, pp. 29-43.

Gonzalbo Aizpuru, Pilar, "La familia novohispana y la ruptura de los modelos", en Colonial Latin American Review, Ix: 1 (2000), pp. 7-19.

GonZalbo Aizpuru, Pilar (coord.), Familias novobispanas. Siglos XVI al XIX. Seminario de Historia de la Familia, México, El Colegio de México, 1991.

Guzmán Vázquez, Antonio y Lourdes Martínez O. (eds.), Del dicho al hecho... Transgresiones y pautas culturales en la Nueva España, México, Instituto Nacional de Antropología e Historia, 1989.

Kuznesof, Elizabeth Anne, "Raza, clase y matrimonio en la Nueva España: estado actual del debate”, en Gonzalbo Aizpuru (coord.), 1991, pp. 373-388. 
Lira, Luis Felipe, "Introducción al estudio de la familia y los hogares en América Latina”, Documento de trabajo núm. 10, Santiago de Chile, Centro Latinoamericano de Democracia, 1975.

Lokken, Paul, "Génesis de una comunidad afro-indígena en Guatemala: la villa de San Diego de la Gomera en el siglo Xviı", en Mesoamérica, 50 (ene.dic. 2008), pp. 37-65.

López Cogolludo, Diego, Historia de Yucatán (1688), Campeche, Comisión de Historia, 1955, t. II.

Lucena Salmoral, Manuel, Regulación de la esclavitud negra en las colonias de América Española (1503-1886): Documentos para su estudio, España, Universidad de Alcalá, Universidad de Murcia, 2005.

Masferrer León, Cristina V., Muleke, negritas y mulatillos. Niñez, familia $y$ redes sociales de los esclavos de origen africano en la Ciudad de México, siglo XVII, México, Instituto Nacional de Antropología e Historia, 2013.

Molina Solís, Juan Francisco, Historia de Yucatán durante la dominación española, Mérida de Yucatán, Imprenta de la Lotería del Estado, 1904, vol. 1.

Mörner, Magnus, La mezcla de razas en la historia de América Latina, Buenos Aires, Paidós, 1969.

MotTa SÁnchez, José Arturo, “¿Huellas bantúes en el noroeste de Oaxaca?”, en Velázquez Gutiérrez y Correa Duró (comps.), 2005, pp. 357-410.

Ngou-Mve, Nicolás, El África bantú en la colonización de México (15951640), Madrid, Consejo Superior de Investigaciones Científicas, 1994.

Ortiz Yam, Inés y Sergio Quezada (eds.), Visita de Diego García de Palacio a Yucatán, 1583, México, Universidad Nacional Autónoma de México, 2009.

Palmer, Colin, "México y la diáspora africana: algunas consideraciones metodológicas”, en Velázquez Gutiérrez y Correa Duró (comps.), 2005, pp. 29-38.

Paredes Martínez, Carlos y Blanca Lara Tenorio, "Los trabajadores negros en el inicio del desarrollo económico poblano”, en Antropología. Boletin Oficial del Instituto Nacional de Antropología e Historia, 78 (2005), pp. 23-28. 
Patrón Sarti, Rafael y Enrique González González, “El capitán Martín de Palomar, regidor, encomendero y benefactor: su testamento (Mérida, Yucatán, 1611)", en Estudios de Historia Novohispana, 43 (jul.-dic. 2010), pp. 185-252.

Peniche Moreno, Paola, Ámbitos del parentesco. La sociedad maya en tiempos de la Colonia, México, Centro de Investigaciones y Estudios Superiores en Antropología Social, Miguel Ángel Porrúa, 2007.

Restall, Matthew, The Black Middle: Africans, Mayas, and Spaniards in Colonial Yucatan, California, Stanford University Press, 2009.

Rubio Mañé, J. Ignacio, Discurso de recepción del: D. J. Ignacio Rubio Mañé. Respuesta del académico: Federico Gómez de Orozco, México, Academia Mexicana de la Historia correspondiente de la Real de Madrid, 1943.

Solís Robleda, Gabriela, Bajo el signo de la compulsión. El trabajo forzoso indígena en el sistema colonial yucateco 1540-1730, México, Centro de Investigaciones y Estudios Superiores en Antropología Social, Instituto de Cultura de Yucatán, Instituto Nacional de Antropología e Historia, 2003.

Solís Robleda, Gabriela, Contra viento y marea: documentos sobre las reformas del obispo Juan Gómez de Parada al trabajo indígena, México, Pareceres, Centro de Investigaciones y Estudios Superiores en Antropología Social, Instituto de Cultura de Yucatán, 2003.

Solís Robleda, Gabriela y Pedro Bracamonte y Sosa, Cedulario de la dominación española en Yucatán. Siglo XVI, México, Centro de Investigaciones y Estudios Superiores en Antropología Social, 2010.

Tuirán Gutiérrez, Rodolfo, “Algunos hallazgos recientes de la demografía histórica mexicana”, en Estudios Demográficos y Urbanos, vII: 1 (ene.-abr. 1992), pp. 273-312. Disponible en: <http://estudiosdemograficosyurbanos.colmex.mx/index.php/edu/article/view/843/836>. Acceso, 10 de enero de 2017.

Velázquez, Gutiérrez, María Elisa, Mujeres de origen africano en la capital novohispana, siglos XVII y XVIII, México Instituto Nacional de Antropología e Historia, Universidad Nacional Autónoma de México, Programa Universitario de Estudios de Género, 2006.

Velázquez Gutiérrez, María Elisa y Ethel Correa Duró (comps.), Poblaciones y culturas de origen africano en México, México, Instituto Nacional de Antropología e Historia, 2005.

Victoria OJeda, Jorge y Aurelio Sánchez, "Interetnicidad y espacios de convivencia. Españoles, indígenas y africanos en la Mérida novohispana, 1542-1620”, en Secuencia. Revista de Historia y Ciencias Sociales, 92 (mayoago. 2015), pp. 8-36. 
Villafuerte, María de Lourdes, "Casar y compadrar cada uno con su igual: casos de oposición al matrimonio en la ciudad de México, 1628-1634", en GuZmán Vázquez y Martínez O. (eds.), 1989, pp. 59-76.

Zamora, Romina, "Lo doméstico y lo público. Los espacios de sociabilidad de la ciudad de San Miguel de Tucumán a fines del siglo xviII y comienzos del siglo xix", en Nuevo Mundo, Mundos Nuevos, Debates, 2010, en http:// nuevomundo.revues.org/58257, consultado 14 de enero de 2017.
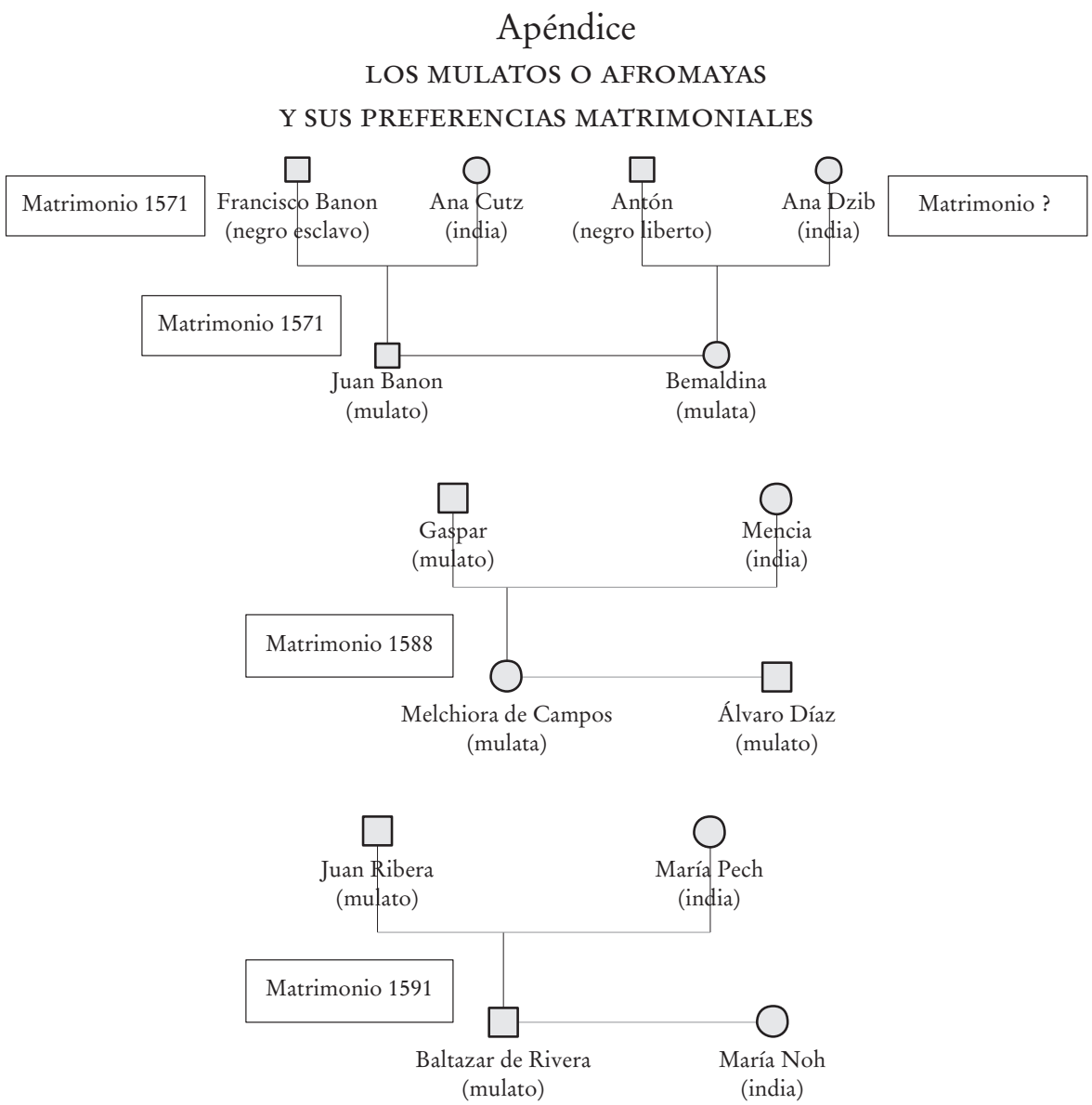

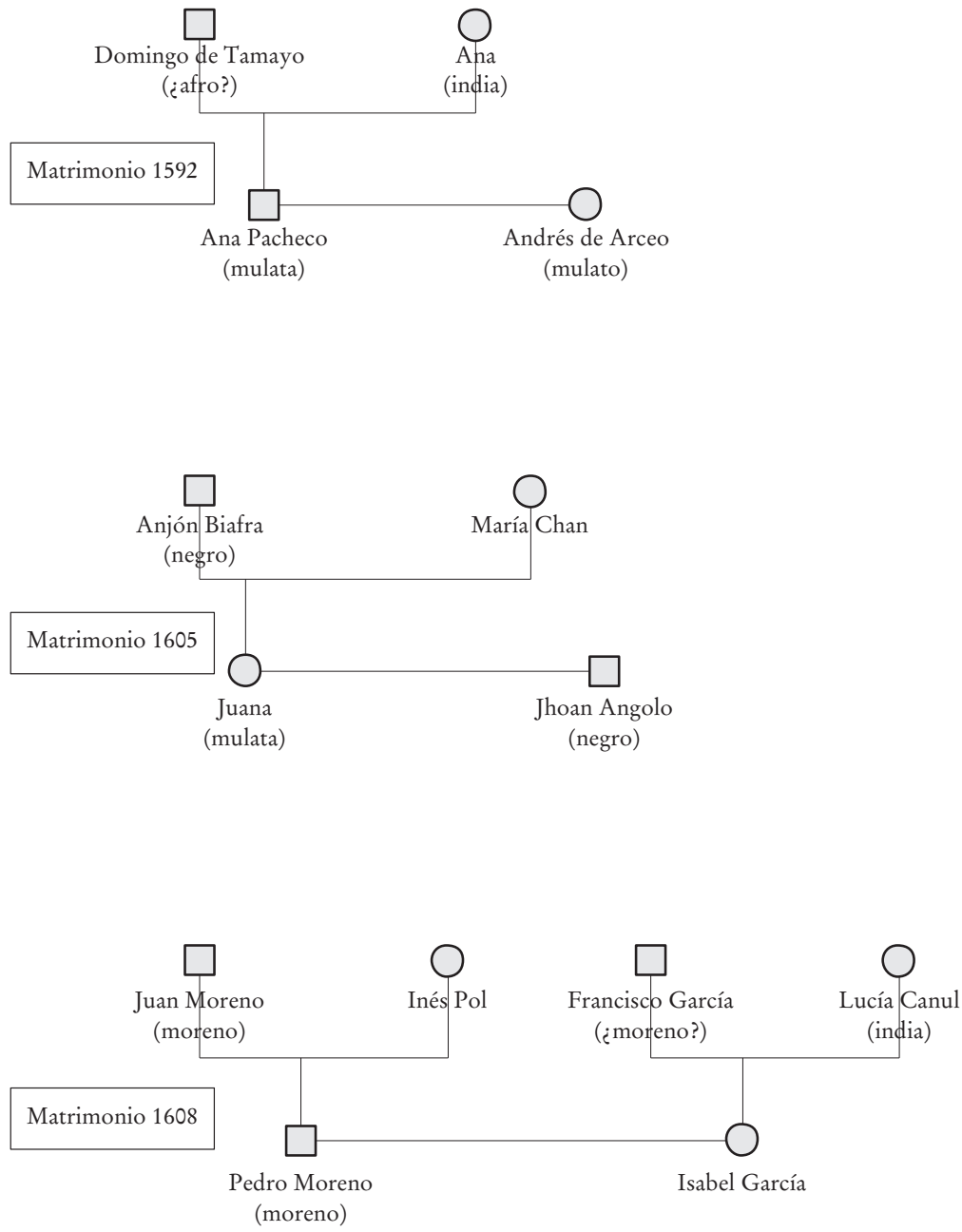